\title{
LAVADO DE ACTIVOS Y LA INCAUTACIÓN DE BIENES COMO MEDIDA CAUTELAR
}

MONEY LAUNDERING AND SEIZURE OF ASSETS AS A PRECAUTIONARY MEASURE

\author{
Dr. Luis Alberto Núñez Lira \\ Universidad César Vallejo \\ ORCID: 0000-0003-3542-9117 \\ lnunezl@ucv.edu.pe \\ Abogada Yasmin Sara Castillo-Palomo \\ Universidad César Vallejo \\ ORCID: 0000-0001-7935-9080 \\ yasmincastillo703@gmail.com \\ Mtro. Jesús Enrique Núñez Untiveros \\ Universidad Privada del Norte \\ ORCID: 0000-0001-9069-4496 \\ jesus.nunez@upn.edu.pe \\ Perú
}

\section{SUMARIO}

- Introducción

- Método

- Resultados y Discusión

- Conclusión

- Fuentes de información

\section{RESUMEN}

El propósito de la investigación fue analizar cómo el Estado se protege del lavado de activos a través de medidas cautelares de incautación de bienes, que en muchos casos la afectación de los bienes patrimoniales a terceros es excesiva, en la medida que los actuales propietarios adquirieron los bienes con buena fe. Por ello, los presupuestos establecidos por la Primera Fiscalía Supra Provincial de Lavado de Activos y Pérdida de Dominio, genera afectación en los investigados, donde el titular de la acción penal -Ministerio Público- genera efectos muchas veces desproporcionados. La investigación utilizó una metodología cualitativa, donde se triangularon metodologías, hallazgos y entrevistas a expertos -Fiscales Superiores Nacionales y Supranacionales- en la temática. Esta metodología ha permitido, a pesar de las controversias, generar opiniones y conclusiones sobre el efecto de estas acciones y que permitirán tener una perspectiva sobre los efectos de los procedimientos procesales $\mathrm{y}$ hacer de conocimiento de la colectividad jurídica los efectos que acarrearía la aplicación de las medidas de manera desproporcionada.

\section{ABSTRACT}

The purpose of this research was to analyze how the State protects itself from money laundering through precautionary measures to seizure of assets. In many cases, the 
affectation of property assets to third parties is excessive, as regards they acquired the assets in "good faith". Therefore, the budgets established by the First Supraprovincial Prosecutor's Office for Money Laundering and Loss of Domain have an impact on investigated people, where the representatives of the criminal actions - Public Ministry - generate effects, being often incommensurate. The research used a qualitative methodology, where methodologies, findings and interviews with experts - National and Supranational Top Prosecutors - were triangulated on the topic. This methodology has allowed, despite the controversies, to generate opinions and conclusions about the effect of these actions. This will allow to have a perspective on the effects of the procedural procedures and to provide legal collective that would lead to the application of the measures disproportionately.

\section{PALABRAS CLAVE}

Encierro; derechos educativos; aprendizaje; co-presencia.

\section{KEYWORDS}

Confinement; educational rights; learning, co-presence.

\section{INTRODUCCIÓN}

La problemática del presente trabajo aborda una de las instituciones jurídicas del área procesal cuyo nombre es incautación, teniendo relevancia jurídica penal y civil; asimismo, esta figura jurídica tiene un uso frecuente por los representantes de la acción penal, sobre todo cuando se trata de un delito complejo como el de Lavado de Activos, que tiene como tendencia destruir la economía de un país; corromper a las autoridades; y dar inseguridad jurídica a la sociedad.
La fiscalía a través del Acuerdo Plenario $\mathrm{N}^{\circ}$ $01-2017$ tiene la potestad de realizar las investigaciones correspondientes solo con la simple sospecha reveladora y utilizar las medidas coercitivas reales, en este caso la incautación; sin embargo la presunción de haber cometido un delito no es suficiente para el uso de esta medida, dado que acarrea una indefensión a aquellos terceros que están dentro de una investigación, que no tienen relación alguna, pero los operadores de la acción penal, tienden a enfrascar a todos por igual y es en este punto donde se ocasionan lesiones patrimoniales con aquellos terceros que de buena fe adquirieron inmuebles o como en la gran mayoría de casos sufrieron afectaciones patrimoniales mediante el delito de usurpación y estafa.

Visto desde esta perspectiva, el Ministerio Publico tiene como una de sus atribuciones incautar los bienes muebles e inmuebles que han sido obtenidos con activos de origen no lícito, medida que se realiza a través de la presunción del lavado de activos que se demostrará en el transcurso del proceso penal, originando una afectación a aquel bien de propiedad de la persona que supuestamente esté relacionada con dicho delito complejo.

Sin duda, la figura de la incautación es un procedimiento que da seguridad, convirtiéndose en una garantía de reparación del supuesto daño cometido al Estado. En esa línea lo establece el Decreto Legislativo $\mathrm{N}^{\circ} 957$ al señalar que la incautación de los bienes muebles e inmuebles sirve como prueba para la comprobación del delito cometido o para su esclarecimiento; de la misma forma Gil (2016) manifiesta que las medidas cautelares son usadas por las instituciones para proteger y salvaguardar los derechos reales que puedan estar expuestos a peligro.

También se debe indicar que esta medida cautelar se interpondrá siempre y cuando 
haya un hecho ilícito generador del activo y una imputación concreta del delito; pero el art. 10 del Decreto Legislativo $\mathrm{N}^{\circ} 1106$ indica que la competencia de este delito y su nacimiento ilegal debe ser presumible por el representante de la acción penal y ante esta connotación se tomará las acciones pertinentes, siendo una de ellas utilizar las medidas cautelares reales como la incautación de los bienes muebles e inmuebles, la cual es usada sin antes haber realizado una imputación concreta, contradiciendo el art. 316 del Decreto Legislativo $\mathrm{N}^{\circ}$ 957, que indica que la incautación se realiza siempre y cuando exista una trasgresión de la norma de manera concreta.

Es por ello que a través del proceso se indicará el uso correcto de la incautación y su utilidad, cuando se esté frente a una investigación, en donde la fiscalía a través de sus indagaciones realice los actos de embargo, decomiso, incautación, de forma coercitiva amparada en el Decreto Legislativo $\mathrm{N}^{\circ} 1106$, normativa que contempla: la lucha eficaz contra el delito de lavado de activos.

Finalmente, la incautación es una de las medidas coercitivas reales, contando con el análisis de las diversas normas nacionales e internacionales, doctrinas y jurisprudencias correspondientes a este tipo de medida, de esta forma tendremos un mejor entendimiento sobre su aplicación y sus efectos, si esta medida no es usada de manera correcta.

En referencia a los estudios realizados por Bidal, (2015) y UNODC, (2019), coinciden en que las medidas cautelares limitativas del patrimonio deben respetar los derechos fundamentales, no obstante, debe tenerse presente que la administración de cada bien incautado deben ser conforme a una ley específica; UNCAC, (2019) señala que las normas que determinan este tipo de medida no deberán tener conexión con alguna gestión o distribución pública, ya que los activos deben tener una administración diferente y particular, indicándose que los bienes al restituirse deben ser compensados. Santander, (2018) señala que las medidas procesales coercitivas han evolucionado $\mathrm{y}$ esto se debe a la jurisprudencia y a la extinción de dominio, la cual tiene como objetivo obtener aquellos activos que han sido adquiridos de manera ilícita. Escamilla, (2017) refiere que en México, las medidas cautelares que se dan en el derecho penal no abarcan otras como la extinción de dominio, porque generan conflicto en su interpretación, así como también la no investigación de más figuras procesales; es decir, no hay la oportunidad de traer alguna norma supletoria en el derecho; Torres, (2018) manifiesta que con la prueba indiciaria, se tiene otro tipo de tratamiento, por lo que los representantes de la ley tienen la misión de probar a través de las medidas, las actividades ilícitas.

En atención a la problemática, las medidas cautelares tienen una relevancia importante, sobre todo cuando se está teniendo como respaldo el principio de imputación necesaria, que es importante no solo para determinar un delito sino también para pedir un requerimiento al magistrado, si este presupuesto principal se obvia por parte del Estado, entonces la persona estaría en un estado de indefensión (Martínez, 2016).

A nivel de la doctrina, el mecanismo procesal de la incautación es una de las figuras más emblemáticas en el derecho, en donde a través del tiempo sigue siendo usada como medida cautelar y su nacimiento es a través de la doctrina romana. UNAM, (2015) recopilo el Codex (529 D.C.) conformado por el Digesto, novelas, institutas, en donde señala que el modo de resarcir un daño ocasionado era a través de la Lex poetelia papillia, la cual nació para abolir el nexum, en donde la muerte o la esclavitud de la res (ciudadano romano) lo 
disponía el afectado. Ante esta realidad, la doctrina romana encabezada por el Emperador Justiniano abolió esa costumbre y señaló que ante una deuda o daño ocasionado, el afectado se cobraría con los recursos patrimoniales para restituir el daño y si la persona que cometió el daño consigue pagar la deuda adquirida, entonces el bien regresaba a sus manos. Al pasar el tiempo la figura cambio de nombre a Pignoris Capio, en donde se coaccionaba al deudor, el tribuno determinaba a través de su imperium el embargo o el secuestro del patrimonio.

Así, la doctrina italiana marco el derecho procesal en el siglo XX, siendo uno de sus máximos representantes Chiovenda (1948), quién refiere que las medidas cautelares son azioni assicurative (acciones aseguradoras), señalando que estas intervenciones legales son medidas provisorias, dado que al realizar estas providencias asegura de manera oportuna la restitución de lo afectado; asimismo el Estado, en su autonomía, puede cautelar todos los bienes de las personas aunque la persona no tenga conocimiento de esto ya que es un derecho fundamental, conociéndose a este argumento como el derecho de providencia.

Roig, (2016) refiriéndose a esta medida como diferente a una sentencia, dado que no tiene vinculación con la culpabilidad $\mathrm{y}$, además, los magistrados alemanes señalan que solo es el resultado accidental de una futura sentencia, dado que, para realizar este tipo de medida debe tener indiscutiblemente base penal y reclamación civil que este aunado al proceso seguido.

Ante esto, el maestro italiano Conderelli (1985), recalca que el accionar de aquel que realice de manera ilegítima e ilícita y a su vez consigue una finalidad económica o un estatus ante la sociedad infringiendo la norma procesal, estaría condenando a la sociedad a hechos ilícito de nunca acabar, no obstante, se debe tener la certeza que al interponer una medida cautelar sobre los bienes estos deben ser de procedencia ilícita.

En la jurisprudencia internacional, Yáñez (2015) cita la sentencia CT524-05-2005, donde refiere que no solo se debe considerar una medida cautelar como acto de ejecución sino también como una acto jurídico amparado por los organismos internacionales que resguarda los derechos fundamentales y tiene como particularidad la jurisdiccionalidad, instrumentalidad provisionalidad y proporcionalidad. En otras palabras, estas medidas son ordenadas por el poder judicial, que deben estar vinculadas previamente a la investigación a través de una orden juridicial, transitoria y de corto tiempo. Para interponer esta medida cautelar los representantes del Estado deberán tener certeza de que el bien inmuebles ha sido adquirido con activos ilícitos y de no ser cautelado se corre el riesgo de que este bien sea donado o transferido y por tanto no garantiza el pago de la reparación civil al Estado y sociedad.

El Poder Judicial Argentino (2018) determinó en el Exp. $N^{\circ} 46940$ - 2011 CA4, las medidas cautelares tienen que tener fines idóneos y proporcionales que aseguran el decomiso; asimismo, los reglamentos están decretados para tener a salvo los derechos de reposición o devolución e indemnización a los terceros.

La Corte Suprema de Justicia de Costa Rica (2018) referente al Exp. $\mathrm{N}^{\circ}$ 001143-2010, dictaminó que las medidas cautelares no tienen naturaleza sancionadora, puesto que al interponerlas son solo de carácter temporal y preventivo, el tiempo puede durar de manera corta o durante lo que lapso de tiempo del proceso, deben ser licitas y jurídicamente posibles, debe tener una buena motivación, esta medida es de efecto asegurativas.

De la misma forma, podemos apreciar la existencia de jurisprudencia nacional, 
emitida por el Poder Judicial (2018) en el Exp. $\mathrm{N}^{\circ} 249-2015-40$, en el que se señala que toda medida cautelar tiene como fundamento el principio de rogación, el cual es importante para interponer cualquier medida cautelar o medida de coerción real, de esa forma el Estado se asegura los bienes presumiblemente ilícitos. Esta figura procesal tiene naturaleza excepcional dado que surge por necesidad para garantizar y consolidar una ejecución judicial, al igual que es naturaleza provisional o transitoria.

El Poder Judicial (2018) en el Exp. $\mathrm{N}^{\circ}$ 0011-2017-43-1801-SP-CI-01, refiere que la adecuación de las medidas cautelares debe ser imprescindible, dado que estas medidas tienen como prioridad ser eficaces y proporcionales ya que solo pueden concederse si son estrictamente necesarias.

Asimismo, a nivel nacional se realizan muchas incautaciones para resguardar los bienes que han sido comprados con activos ilícitos, de allí la necesidad de usar este tipo de mecanismos.

El Decreto Legislativo $\mathrm{N}^{\circ} 736$, integró los artículos 296-A - 296-B, que indicaban como agravante el tráfico ilícito de drogas; sin embargo, esta infracción a la ley se transfirió a los delitos contra el patrimonio en la Ley $\mathrm{N}^{\circ} 25404$, que indica tiene configuración con el delito de receptación y lo dispuso en el Art 195 del Código Penal en 1992, para que después la Ley $\mathrm{N}^{\circ} 25482$ lo vuelva a colocar en el área de salud pública; igualmente a principios del año 2002, la Ley $\mathrm{N}^{\circ} 27765$ cambia esencialmente la forma dejando el nombre de "Lavado de dinero" para designarle "Delito de Lavado de Activos", de esta forma se extendió la finalidad del delito, aceptando otras formas delictivas, al igual que se constituyen y asientan los comportamientos típicos y las disposiciones normativas para las investigaciones y penas en dicho delito.
No obstante en el año 2004, se realiza una variación en el tipo penal por la Ley $\mathrm{N}^{\circ}$ 28355 y determina algunos agravantes, para volver a ser modificada con el Decreto Legislativo $\mathrm{N}^{\circ}$ 986. Sin embargo, el Decreto Legislativo $\mathrm{N}^{\circ} 1106$ denominado de "La lucha eficaz contra el lavado de activos y otros delitos relacionados a la minería ilegal y crimen organizado", realiza una renovación primordial en los preceptos, resaltando materias procesales que se pueden usar para dar mayor eficacia a las pesquisas de este delito, así como las medidas coercitivas personal y real.

Por tanto, en nuestra jurisprudencia nacional esta figura procesal ayuda a preservar el bien incautado y sobre todo le garantiza al Estado que va a ser resarcido, siempre y cuando se demuestre en una sentencia firme que la incautación de bienes ha sido adquiridos con activos ilícitos y su incautación dará un beneficio al país; asimismo, nuestro país no es ajeno a esta medida cautelar. El Poder Judicial (2009) en el Exp. $\mathrm{N}^{\circ}$ 2009-2604-25, señala que la incautación es una medida limitativa y tiene como propósito afectar el derecho a la propiedad de aquel que sea titular del bien inmueble o bien mueble, y como finalidad tiene el aseguramiento de aquella evidencia que sirve para dar veracidad el delito cometido o su participación en él; asimismo, el Acuerdo Plenario $\mathrm{N}^{\circ}$ 5-2010/CJ-166, refiere que en la incautación siempre debe de contar con un requerimiento judicial y este debe ser confirmado de inmediato, al igual que esta medida debe realizarse de manera inmediata, no puede haber tardanzas y si en el caso cae en tardanza, se examinara a través del principio de proporcionalidad.

Garay (2013) determina que la incautación es una medida procesal $y$ tiene una clasificación jurídica la cual se divide en dos: la primera es la búsqueda de pruebas dado que su empleo es conservativo, ya que de esa forma se puede mantener $y$ 
resguardar una prueba material, que después se convertirá en un juicio como una prueba determinante, la segunda es restrictiva, ya que, previene el ocultamiento de los bienes del investigado, también se llama instrumental puesto que los bienes tienden a ser el elemento que está relacionado con el delito y esto esta descrito de manera taxativa en los arts. 218 al 223 del Código Procesal Penal.

El Recurso Casación (2018) N 864-2017 explica que la incautación es la medida que recae a los bienes que solo estén vinculados con el delito, tiende a afectar de forma necesaria a quien lo posea, siendo este el investigado o no, en este caso si es el investigado tiene que tener como exigencia la mala fe, no obstante el decomiso no podrá darse si es que el bien ha sido adquirido por transferencia al tercero de buena fe.

Consecuentemente, tenemos las categorías de investigación, las cuales brindaran el sustento necesario en este estudio de un delito que es capaz de vulnerar y afectar a todo un país, ya sea de manera institucional, económica y moral; sin embargo, se debe tener en cuenta las diferentes afectaciones que se dan en una incautación cuando esta es realizada sin una base jurídica, por ello como primera categoría de esta investigación es la afectación del patrimonio, el cual es afectado ante este delito, a través de artimañas o engaños este se llega a perder a veces, a sabiendas porque se realiza a través de una compra y venta, pero en el caso de terceros de buena fe o de personas de bajos recursos que no sabían lo que estaban firmando o que estaban creyentes de una entidad bancaria que resultó ser una fachada, ante ello su patrimonio sufre afectación, por eso la sub categoría de esta primera fase es el delito de usurpación y estafa.

En efecto, este delito al cometerse vulnera la defensa del dueño de la propiedad, que a través de engaños fue despojado de su patrimonio, a través de la modalidad de las cooperativas fantasmas que no son más que fachadas dedicadas a quitar propiedad a sus verdaderos dueños. El Ministerio Publico (2019) Primera Fiscalía Supra provincial de Lavado de Activos - Carpeta Fiscal N ${ }^{\circ} 24-$ 2014, la cual cuenta con 2400 tomos fiscales con 482 personas vinculadas en este caso, teniendo en su haber a diferentes funcionarios públicos, así como la creación de cooperativas ficticias causando un daño a personas naturales y jurídicas de más de S/1000 000 000.00, los cuales han afectado a la economía del Estado, así como también de más 150 inmuebles incautados, 600 inmuebles adquiridos por usurpación $\mathrm{y}$ estafa, algunos de estos inmuebles incautados los dueños no tenían idea, del delito que se les estaba vinculando.

Por otra parte, en nuestra legislación se tiene presente que para demostrar este tipo de delito previo que es la usurpación, las pruebas por parte de los investigados, no son suficientes, dado que ante un delito complejo la buena fe deberá demostrarse, al igual que la inocencia deberá probarse, cosa que se contradice con nuestra Constitución Política que en el art. 2, inciso 24, literal e., establece que toda persona tiene derecho a ser considerada inocente hasta la demostración de su culpabilidad a través de una sentencia firme. En todo caso es la fiscalía la que debe probar la culpabilidad de manera concreta, no debe ser por presunción, sino de imputación concreta para proceder con las incautaciones.

De igual forma se debe tener presente el art. 2 inciso 16 de la misma Carta Política, el cual consagra el derecho a la propiedad, en concordancia con el art. 70 que preceptúa que el Estado garantiza la propiedad porque es inviolable, señalando así que la persona está protegida al igual que el bien inmueble adquirido.

En el caso de la segunda sub categoría, el delito de estafa se debe tener presente que 
uno de los factores por el cual se comete es para engañar a la persona. El Decreto Legislativo $\mathrm{N}^{\circ}$ 635, arts. 196, 196 - A y 197, señalan que este delito es a través del engaño, en donde se realice compra y venta bienes e inmuebles, participando dos a más personas y se aproveche para usufructuar a través de ellos, como también despojando del bien a sus legítimos dueños a través de un ardid, este delito previo está vinculado al delito en cuestión.

\section{El Ministerio Publico (2019) Primera} Fiscalía Supra Provincial de Lavado de Activos - Carpeta Fiscal No 24 - 2014, señala que al igual que la usurpación, la estafa se cometía a través de firmas en papeles en blanco aduciendo que las firmas eran para registrar el bien inmueble no para ceder el terreno, al igual que en la compra de terrenos que no existían y la apariencia de que el título de propiedad era verdadero, cuando en verdad era un engaño de parte de una organización criminal.

De igual forma, en nuestra realidad social, se debe indicar que en este delito complejo, el delito previo de estafa está siempre presente en la gran mayoría de casos complejos, esto lo podemos corroborar en la Carpeta Fiscal $\mathrm{N}^{\circ} 24-2014$ en el caso Orellana, que está bajo la custodia del Ministerio Público, como también en la Carpeta Fiscal No 16 - 2014 y la Carpeta Fiscal $N^{\circ} 31$ - 2018, casos que se pone como ejemplo para indicar que cada uno de ellos tiene un concurso de delitos y de personas vinculadas tanto jurídicas como naturales.

Whisker y Lokanan, (2019) refieren que esta forma de captar dinero no es la única que existe, dado que la estafa digital es frecuente por el crimen organizado, a través del acceso a internet, compras on line $\mathrm{y}$ gusanos cibernéticos en las cuentas de los usuarios a través de sus apps bancarios; Soudijn, (2019) indica que en el reporte del 2004 - 2016 que este delito en los países bajos tiene un índice mayor, por las nuevas modalidades de fraude y estafa, estas no solo se da por el engaño face to face, sino por dinero recibido por internet, los cuales se usan de cuenta interbancaria a cuenta así desaparecen el dinero ilícito y lo convierten en licito.

La segunda categoría denominada pérdida de patrimonio, se da a través de una medida coercitiva real, donde los representantes de la acción penal hacen un pedido al magistrado. En la legislación peruana la Corte Suprema de Justicia (2011) refiere el Acuerdo Plenario N ${ }^{\circ}$ 7-2011/CJ-116 señala que las medidas coercitivas reales, son sucesos escritos en las resoluciones judiciales, regida por el principiodispositivo, en donde se busca garantizar el resultado económico del delito. Así, el Decreto Legislativo $\mathrm{N}^{\circ} 1106$, en su art. 9 establece la incautación sobre los bienes que han sido adquiridos con recursos ilícitos, estos mecanismos se aplican asegurando el pago de la reparación civil y asegurar la sanción penal en el aspecto patrimonial del lavador.

De igual forma, se debe señalar que antes de dar esta medida, previamente se ha tenido que realizar una investigación en sede fiscal conjuntamente con la policía para realizar las diferentes investigaciones; Cáceres, (2017) señala que estas medidas de coerción real tienen como fin mantener $y$ custodiar el bien del investigado o imputado, como también la del tercero civil. Si en la investigación fiscal se detecta la responsabilidad de que los bienes inmuebles han sido adquiridos con dinero ilícito, y esto es demostrado ante un juicio y como resultado se tiene una sentencia firme y condenatoria, todos los bienes pasan a manos del Estado, asimismo el condenado se responsabilizará de realizar el pago de la multa impuesta como las costas procesales.

Se debe acotar que estas sospechas tienen como una de sus finalidades la incautación 
de bienes, la cual procede durante la indagación patrimonial y hasta antes de la audiencia de indagación de pruebas, una vez incautado el bien, este pasa por rigurosas verificaciones; Bustamante $\mathrm{y}$ Elizalde, (2016) determinan que este tipo de medida tiene como principal propósito garantizar la asistencia del procesado, evitando la obstrucción, ocultamiento o simulación de la verdad; asimismo, Kleemans, (2015) refiere que las incautaciones son de vital importancia dado que al activar esta medida coercitiva, le da la oportunidad al Estado a tener un seguro con una probabilidad del $90 \%$ a favor del Estado, siempre y cuando estas sean licitas $\mathrm{y}$ no perjudiquen a un tercero y si lo hiciesen se estaría vulnerando el derecho a la persona.

La tercera categoría de este estudio es la administración del patrimonio, Castello y Segovia (2015) indican que para el proceso de incautación y/o decomiso es necesario que esté basado por dispositivos internacionales para la protección de derechos de la persona tanto fundamentales como patrimoniales. No obstante, Keesoony (2016) refiere que las leyes internacionales, para recobrar los bienes, son severas, porque estamos ante un delito no solo complejo sino internacional; sin embargo, Álvarez (2018) indica que en la Corte colombiana se estableció que la extinción de dominio es un acto constitucional, ya que al identificar bienes muebles o inmuebles adquiridos con dinero ilícito de tráfico de influencias, narcotráfico, lavado de activos, etc., y a consecuencia perjudique a la economía nacional y a la sociedad, la extinción es inmediata, y esto se da a través de una resolución judicial extinguiendo el dominio, esta no es una medida cautelar, sino una medida definitiva.

En nuestra normativa legal se derogó el Decreto Legislativo $N^{\circ} 1104$, por el Decreto Ley $\mathrm{N}^{\circ} 1373$, que es la ley de extinción de dominio, que tiene por finalidad recobrar los bienes que han sido adquiridos de manera ilícita perjudicando la economía del Estado. Una vez adquirido el bien mueble o inmueble el Estado dispone su destino y administración, es así que para interponer y ejecutar la extinción de dominio tiene dos fases, la investigación e inspección patrimonial está a cargo del fiscal especializado, el fiscal requiere la incautación de bienes al juez especializado y los presupuestos para su ejecución.

La cuarta categoría tiene como fondo principal el destino del bien ante el delito y para ello se debe señalar que cuando un bien es incautado, este se encuentra administrado por la entidad PRONABI, hasta que el juez indique su restitución. Si en el caso no se restituye el bien, esta pasa directamente al Estado, el cual lo tomará como reparación civil, para ello se debe determinar a través de una sentencia firme que los bienes han sido adquiridos con dinero ilícito y que la medida cautelar predecesora a la sentencia ha sido correcta $\mathrm{y}$ no ha afectado ningún derecho fundamental.

Chanjan, Solís y Puchuri (2018) refieren que se debe asegurar nuestro régimen de sentencia, sobre todo cuando el fallo es condenable, y que siempre se realice una investigación eficaz para que no se cometa una equivocada valoración. La Ley $\mathrm{N}^{\circ}$ 30737 garantiza la inmediatez de la Reparación Civil al Estado en casos de corrupción y conexos; el artículo 2 señala que al Estado se le indemniza a través de sentencia firme por delitos administrativos en la gestión pública, lavado de activos o equivalentes, que deberán ser demostrados, a partir de la publicación de esta norma, nuestro país puede reclamar la reparación civil que corresponde en este tipo de delito complejo, por ello el compendio de normas dentro de este decreto legislativo ayudan a resarcir no solo al país, sino a toda la sociedad, asimismo las medidas para garantizar la reparación civil por: 
transferencias al exterior, adquisición y retención del fideicomiso de retención y reparación, retención de importes a favor del Estado, anotación preventiva.

La quinta categoría de este estudio es la devolución del patrimonio, consideramos importante entender este punto desde sus orígenes, evolución y tratamiento en la actualidad, por ello el patrimonio es el compendio de vínculos jurídicos y dinerarios correspondiente a una persona la cual tiene deberes y obligaciones, asimismo este conformado por el activo y pasivo, en este caso el primero son los bienes vinculados a la persona y el segundo son gravámenes que tiene la persona que cumplir con dinero.

Al respecto, se presume que todos los patrimonios y posesiones de los investigados son de origen ilícito y por lo tanto son investigados hasta que la pericia determine la existencia de un desbalance patrimonial o no. Brenig, Accorsi, y Müller (2015) señalan que las actividades ilícitas tienen como obligación buscar diferentes canales para colocar el dinero obtenido, a través de la compra de viene inmuebles, acciones, patente tecnológicos, de esa forma es difícil, que los expertos puedan descubrirlo, sin embargo para Savona y Riccardi (2017) refieren que, en Europa los patrimonios adquiridos con activos ilícitos son los más rentables para las bandas criminales dedicadas a este tipo de delito y para detectarlo se tiene que realizar un estudio impecable y preciso que detecte estas compras, es por ello que estos estudios tienden a demorarse pero son lo suficientemente determinantes que no dejan la posibilidad de generarse ninguna duda razonable por eso sería imposible de rebatir la decisión tomada en un juicio.

Por otro lado, si estos patrimonios resultan ser obtenidos de manera lícita, pero están comprometidos en la incautación, el afectado puede pedir la variación de la medida, en nuestro ordenamiento jurídico también se prevé estas salvedades. El Decreto Legislativo $\mathrm{N}^{\circ}$ 957, en su art. 318 inciso 3 señala que si el bien incautado puede ser devuelto a cambio de un depósito, es entregado provisionalmente al afectado teniendo en cuenta que esta medida puede ser revertida.

Se debe señalar que la persona se presume inocente como principal garantía para la persona, Calanmadrei, (1986) señala que este principio es a pedido por la persona que ha sido vulnerada en su derecho y tiene la necesidad que el Estado lo proteja a esto se le llama la autonomía de voluntad, por lo que toda persona tiene el derecho de pedir al Estado su protección cuando se esté perjudicando su derecho, así como el retorno del bien que se realiza a través de una sentencia firme. El Decreto Legislativo $\mathrm{N}^{\circ} 957$ art. 320 refiere que una vez dictada la sentencia que señale la licitud del bien o del auto de sobre seguimiento donde pone fin al proceso, se le entrega el bien incautado.

El problema específico en esta temática nos impone la pregunta ¿Cuáles son los presupuestos de las medidas cautelares que afectan el patrimonio de un investigado ante un caso llevado por la Primera Fiscalía Supraprovincial de lavado de activos y pérdida de dominio 2019? El objetivo de este estudio es determinar los presupuestos de las medidas cautelares que afectan el patrimonio de un investigado ante un caso llevado por la Primera Fiscalía Supraprovincial de lavado de activos y pérdida de dominio 2019.

\section{MÉTODO}

La metodología empleada son un conjunto de procesos que se ha realizado para la ejecución de la indagación científica. Gómez, (2012) indica la revisión permanente y constante de los hechos que son objetos de investigación, debiendo 
retornar -ida y vuelta- para la deducción permanente en la búsqueda de indicadores o factores emergentes, para el continuo de la investigación; por ello se puede señalar que la metodología es parte primordial de un estudio y a través de sus técnicas permite demostrar su teoría del problema que hayan planteado. Así, la investigación ha utilizado la triangulación de metodologías como el estudio de casos, hermenéutico y teoría fundamentada (Piñeiro, Rivera y Esteban 2019).

Como primer proceso de la investigación se estableció la matriz de categorización, donde se establece las categorías, subcategorías, fuentes, técnicas e instrumentos.

Tabla 1:

\begin{tabular}{|c|c|c|c|c|}
\hline Categoría & Subcategoría & $\begin{array}{c}\text { Fuente } \\
\text { Informante }\end{array}$ & Técnicas & Instrumento \\
\hline $\begin{array}{l}\text { Afectación del } \\
\text { Patrimonio }\end{array}$ & $\begin{array}{l}\text { Usurpación } \\
\text { C.P. ART 202 INC.2 y } 4 \\
\text { Estafa } \\
\text { C.P. ART 196, } 196\end{array}$ & \multirow{5}{*}{$\begin{array}{l}1^{0} \text { Fiscalía } \\
\text { Supra - } \\
\text { provincial de } \\
\text { Lavado de } \\
\text { Activos }\end{array}$} & \multirow{5}{*}{ Entrevista } & \multirow{5}{*}{$\begin{array}{l}\text { Guía de } \\
\text { preguntas de } \\
\text { entrevista }\end{array}$} \\
\hline $\begin{array}{l}\text { Perdida del } \\
\text { Patrimonio }\end{array}$ & Medidas Coercitivas Reales & & & \\
\hline $\begin{array}{l}\text { Administración } \\
\text { del Patrimonio }\end{array}$ & $\begin{array}{l}\text { Ejecución de Pérdida de } \\
\text { Dominio DL. } 1373 \\
\end{array}$ & & & \\
\hline Destino del bien & $\begin{array}{l}\text { Reparación Civil y } \\
\text { Beneficio al Estado }\end{array}$ & & & \\
\hline $\begin{array}{l}\text { Devolución del } \\
\text { Patrimonio }\end{array}$ & $\begin{array}{l}\text { Variación de Medida } \\
\text { Reexamen de medida }\end{array}$ & & & \\
\hline
\end{tabular}

Matriz de construcción de categorias y subcategorías

Fuente y elaboración: Propia

El escenario de la investigación es el Distrito Fiscal de Lima, operadores jurídicos especialistas en incautación $\mathrm{y}$ casos emblemáticos del Delito de Lavado de Activos, los cuales eran entrevistados y brindaron sus conocimientos para este estudio, al igual que las fuentes documentadas las cuales son adquiridas los diferentes artículos científicos tanto nacional e internacional, los cuales ayudaran a dar una mejor perspectiva.
Se caracterizaron sujetos-instituciones que brindaron información relevante para la investigación, en relación a ello los entrevistados fueron dos Fiscales Adjuntos Superiores de la Fiscalía Superior Nacional de Lavado de Activos y Pérdida de Dominio de Lima, al igual que tres fiscales adjuntos supra provinciales de la Fiscalía Supra provincial de Lavado de Activos y Pérdida de Dominio de Lima y dos abogados litigantes especialistas en la materia de estudio. Asimismo, se realizó el análisis de diversos expedientes jurídicos sobre la casuística tratada.

Se ha tenido presente los diversos aspectos que son relevantes para el objetivo de este estudio, por lo que el escenario en donde se desarrolla este estudio, a través de sus funcionarios, Abogados de la defensa, doctrinarios, artículos científicos, revistas especializadas, opiniones de los expertos sobre incautación y sus efectos ante este delito.

Para la recolección de datos se ha utilizado la Técnica de Entrevista, en donde la herramienta utilizada es la Guía de Entrevista, la cual se realizó a los representantes del Estado como también a los abogados defensores, a través de las respuestas de cada uno de ellos se realizó el análisis correspondiente y de esa forma se obtuvo diversas posiciones que ayudaron a tener una mejor perspectiva en el campo del derecho procesal, al igual que la teoría fundamentada, la cual está constituida por las diferentes doctrinas, análisis de fuentes bibliográficas, artículos científicos etc.

\section{RESULTADOS Y DISCUSIÓN}

Con respecto a la determinación de los presupuestos que afectan el patrimonio de un investigado ante un caso llevado por la Primera Fiscalía Supraprovincial de lavado de activos y pérdida de dominio 2019.

\section{Categoría 1: Afectación del Patrimonio}


Sub Categorías - Usurpación y Estafa Sub - Categoría 1 Usurpación: ¿Cómo se configura el delito de Usurpación ante el delito de Lavado de Activos? y ¿cuáles son sus consecuencias?

\begin{tabular}{|c|c|}
\hline Experto & Respuesta \\
\hline Sáenz 2019 & $\begin{array}{l}\text { Consiste en un todo los } \\
\text { procedimientos con } \\
\text { aparente legitimidad a } \\
\text { bienes y capitales de } \\
\text { origen ilícito, pudiendo ser } \\
\text { de procedencia a través del } \\
\text { delito de usurpación y esto } \\
\text { se da a través del despojo } \\
\text { de una propiedad que } \\
\text { genera el incremento de } \\
\text { capital no justificado. }\end{array}$ \\
\hline $\begin{array}{c}\text { Garavito } \\
2019\end{array}$ & $\begin{array}{l}\text { Es un delito instantáneo } \\
\text { con efectos permanentes } \\
\text { tiene como consecuencia } \\
\text { un daño patrimonial al } \\
\text { agraviado y puede ser } \\
\text { delito fuente del Lavado de } \\
\text { Activos. }\end{array}$ \\
\hline $\begin{array}{c}\text { García } \\
2019\end{array}$ & $\begin{array}{l}\text { Se configura a través del } \\
\text { despojo de un bien } \\
\text { inmueble que genera el } \\
\text { incremento patrimonial de } \\
\text { forma ilícita y no lo puede } \\
\text { justificar ante una pericia } \\
\text { contable. }\end{array}$ \\
\hline $\begin{array}{c}\text { Corvacho } \\
2019\end{array}$ & $\begin{array}{l}\text { Se configura mediante la } \\
\text { violencia que se ejerce } \\
\text { hacia otra, generando el } \\
\text { despojo de una propiedad y } \\
\text { esta al ser tomada de forma } \\
\text { ilícita por parte de una } \\
\text { organización criminal se } \\
\text { convierte en un activo, } \\
\text { como consecuencia el bien } \\
\text { pasa a formar parte de una } \\
\text { organización criminal que } \\
\text { es lavado como un activo } \\
\text { licito }\end{array}$ \\
\hline $\begin{array}{c}\text { Coaquira } \\
2019\end{array}$ & $\begin{array}{l}\text { El delito de usurpación se } \\
\text { puede considerar como } \\
\text { delito fuente, por ser este }\end{array}$ \\
\hline
\end{tabular}

\begin{tabular}{|c|l|}
\hline & $\begin{array}{l}\text { un delito que generan } \\
\text { utilidades ilegales }\end{array}$ \\
\hline Muñoz & $\begin{array}{l}\text { La usurpación es un delito } \\
\text { que afecta un derecho real } \\
\text { de una persona, el mismo } \\
\text { que podría generar } \\
\text { ganancias ilícitas yodrían } \\
\text { ser introducidas a la } \\
\text { economía del país, } \\
\text { configurándose en el delito } \\
\text { en cuestión. }\end{array}$ \\
\hline $\begin{array}{l}\text { La usurpación es un delito } \\
\text { que afecta los derechos de } \\
\text { la persona, ya que es un } \\
\text { derecho patrimonial, por lo } \\
\text { que la usurpación se } \\
\text { configura con la violencia } \\
\text { y al ser tomado de esa } \\
\text { forma podría caer en el } \\
\text { delito en cuestión, la } \\
\text { consecuencia sería el } \\
\text { despojo de un bien para un } \\
\text { nuevo delito que es } \\
\text { obtener un bien de manera } \\
\text { ilícita y hacerlo pasara } \\
\text { como licito }\end{array}$ \\
\hline
\end{tabular}

Fuente y elaboración: Propia

Los expertos coinciden en que la usurpación se configura con la violencia o despojo de un bien y tiene efectos permanentes, el cual daña los derechos de propiedad y que genera ganancias ilícitas, dando la apariencia de licitud; asimismo ante este delito tiende a ser un activo que es pasado como un bien licito, pero al ser investigado este activo tiende a ser injustificado por el presunto lavador.

Bidal, (2015) señala que las medidas cautelares limitativas del patrimonio deben respetar los derechos fundamentales, y estas deben tener una entidad que administre cada bien incautado, asimismo dentro de la doctrina internacional que tiene una gran relevancia jurídica, Chiovenda (1948) anota que las medidas cautelares son acciones aseguradoras y que son medidas provisorias ya que 
aseguran la restitución de lo afectado, no obstante el Estado, en su autonomía, puede cautelar todos los bienes de las personas, aunque la persona no tenga conocimiento de esto, la normativa nacional a través del Decreto Legislativo $N^{\circ} 1106$, indica que para incautar un bien se debe tener solo una presunta sospecha y esto ha sido ratificado en el Acuerdo Plenario $\mathrm{N}^{\circ} 01-2017$, el cual señala que solo basta con presumir el delito, ya que su corroboración se realizará en la investigación.

Si bien es cierto que es un delito complejo y la forma que ataca la economía de un Estado es terrible, puesto que juega con los intereses públicos $\mathrm{y}$ económicos, al realizarse incautaciones de manera indiscriminada, sin antes haber constatado el hecho ilícito, se afecta el patrimonio de un investigado ante el delito.

Por ello, el estudio se enfatizó sobre las consecuencias de la incautación, la cual es una de las medidas que afectan el patrimonio de un investigado ante este tipo de delito, generando una controversia dentro de la doctrina nacional como internacional sobre las medidas cautelares tomadas por los representantes del Ministerio Público, para ello se usó el análisis de la información recibida y por la técnica que se aplicó en el estudio y confrontó con el estudio documental y la jurisprudencia nacional e internacional.

Sub - Categoría 2 Estafa: Pregunta ¿Cómo se configura el delito de Estafa ante el delito de Lavado de Activos? y ¿Cuáles son sus consecuencias?

\begin{tabular}{|c|l|}
\hline Experto & \multicolumn{1}{|c|}{ Respuesta } \\
\hline Sáenz 2019 & $\begin{array}{l}\text { Es una modalidad del } \\
\text { delito contra el patrimonio, } \\
\text { que mediante el engaño, } \\
\text { astucia o ardid procura un } \\
\text { provecho ilícito generando } \\
\text { el crecimiento del } \\
\text { patrimonio sin justificar }\end{array}$ \\
\hline
\end{tabular}

\begin{tabular}{|c|c|}
\hline & $\begin{array}{l}\text { que configurase a su vez la } \\
\text { comisión de este delito }\end{array}$ \\
\hline $\begin{array}{l}\text { Garavito } \\
2019\end{array}$ & $\begin{array}{l}\text { La estafa es un delito } \\
\text { contra el patrimonio que } \\
\text { merma la economía de las } \\
\text { personas, también puede } \\
\text { ser considerado como } \\
\text { delito fuente de Lavado }\end{array}$ \\
\hline $\begin{array}{l}\text { García } \\
2019\end{array}$ & $\begin{array}{l}\text { Delito contra el patrimonio } \\
\text { que mediante el engaño } \\
\text { genera ganancias ilícitas } \\
\text { no justificadas, es un delito } \\
\text { predilecto de las } \\
\text { organizaciones criminales } \\
\text { dedicadas a lavar activos }\end{array}$ \\
\hline $\begin{array}{l}\text { Corvacho } \\
2019\end{array}$ & $\begin{array}{l}\text { Delito contra la propiedad } \\
\text { o el bien de una persona, } \\
\text { que, mediante el fraude, el } \\
\text { timo perjudica aquel que } \\
\text { de buena fe tiene } \\
\text { confianza, siendo de } \\
\text { mucha relevancia, porque } \\
\text { este delito es beneficios } \\
\text { para todo lavador ya que } \\
\text { de manera ilícita obtienen } \\
\text { un bien que dado de forma } \\
\text { licita. }\end{array}$ \\
\hline $\begin{array}{l}\text { Coaquira } \\
2019\end{array}$ & $\begin{array}{l}\text { De la misma manera, que } \\
\text { en el caso de delitos de } \\
\text { Usurpación es en el } \\
\text { presente caso, cuyo delito } \\
\text { fuente es el delito de estafa } \\
\text { de ser pertinente } \\
\text { corresponde abrir } \\
\text { investigación preliminar }\end{array}$ \\
\hline $\begin{array}{l}\text { Muñoz } \\
2019\end{array}$ & $\begin{array}{l}\text { Delito contra el patrimonio } \\
\text { que se configura con el } \\
\text { engaño, el mismo que } \\
\text { genera ganancias ilícitas } \\
\text { podría ser introducido al } \\
\text { sistema económico del } \\
\text { país configurando el Delito } \\
\text { de Lavado de Activos. }\end{array}$ \\
\hline Estela 2019 & $\begin{array}{l}\text { A través del engaño se } \\
\text { configura este delito, las } \\
\text { consecuencias serían que } \\
\text { este genere ganancias y } \\
\text { estas sean insertadas a la }\end{array}$ \\
\hline
\end{tabular}




\begin{tabular}{|l|l|}
\hline economía del país no \\
obstante también perjudica \\
aquel que de buena fe \\
pierde su bien inmueble \\
para convertirlo en activo \\
ilícito.
\end{tabular}

Fuente y elaboración: Propia

Los entrevistados coinciden en que la estafa es un delito contra el patrimonio y genera ganancias ilícitas, como también es delito-fuente ya que pueden obtener ganancias ilícitas aparentando ser licitas generando activos que son insertados a la economía nacional, configurándose el delito de lavado.

Estos delitos son llamados delitos-fuentes del lavado de activos, así lo acreditan Sáenz, Garavito, García, Corvacho, Coaquira, Muñoz y Estela, ya que se configura con la violencia o despojo de un bien y tiene efectos permanentes, el cual daña los derechos de propiedad y que genera ganancias ilícitas, asimismo en nuestra jurisprudencia Nacional el Código Penal Art. 202 inciso 2 y 4 señala las formas en las que el delito de Usurpación se configura a través del engaño, violencia, aprovechamiento de la estima, en donde se apropian del bien inmueble y lo aseguran sin aviso alguno a los verdaderos dueños.

Chirac y Blaj (2018) refieren que este delito va contra las reglas de la sociedad ya que por violencia, confianza o engaño la gran mayoría de personas han perdido sus bienes y están vinculadas a este de hecho ilícito, por lo que una incautación hacia estas personas atentaría contra la presunción de inocencia y el derecho fundamental de la propiedad.

Uno de los casos más controvertidos es el Caso Orellana, el cual a través de la usurpación y estafa se ha beneficiado con un millar de inmuebles generando al Estado una crisis patrimonial y económica; asimismo el delito de estafa es aquel que a través del engaño consigue aprovecharse y realizar actos ilícitos como la venta de un bien inmueble sin avisarle a los dueños sobre el acto jurídico que se va a realizar (compra venta), por lo que nuestra normativa lo tiene tipificado en los arts.196, 196 - A y 197 del Código Penal, en donde señala que este delito se configura a través del engaño, cada vez que se realice compra $\mathrm{y}$ venta de bienes muebles e inmuebles, participando dos a más personas y se aproveche para usufructuar a través de ellos, como también despojando del bien a sus legítimos dueños a través de un ardid, por lo que los artículos científicos internacionales como el de Ackerman y Palifika (2018) refieren que muchas organizaciones criminales de Europa están al asecho de aquellos que no tienen las posibilidades para adquirir préstamos y esto hace que las personas entreguen sus bienes como garantía, hasta que terminen de pagar, pero sus bienes ya son comprados por otros, a veces por altos funcionarios.

Otra modalidad que se ejerce en Europa son las empresas fantasmas, las cuales hacen inversiones $y$ estas realizan depósitos de intereses a las misma personas que han invertido su patrimonio, pero esto solo es una fachada, dado que solo le dan un porcentaje mensual, ya que está invertido en otros delitos, ejemplo tráfico de drogas, tráfico de órganos, armas, vinculándolos en delitos que no cometieron.

Middleton, y Levi (2015) refieren que la estafa hipotecaria es algo sencillo de realizar por parte de los operadores jurídicos, en este caso abogados que laboran en la rama de patrimonios e hipotecas, en esta modalidad los abogados crearon cuentas ficticias en la red y la gente depositaba el dinero para hacer la compra y los que ofertaban sus casas no recibían centavo alguno, es más sus escrituras pasaban a manos de las notarías falsas. 
Por ello, se concuerda con la doctrina nacional, como internacional, en la cual señalan que estos delitos como Usurpación y Estafa son propicios para afectar el patrimonio de cualquier persona y termina siendo usado en el delito de Lavado de activos, mediante el cual se obtiene ganancias de un hecho ilícito, también se concuerda con los entrevistados que señalan que la usurpación y la estafa son delitos fuente y que afectan el patrimonio de manera permanente, ya sea de investigados o de terceros de buena fe, por lo que se cumple con el objetivo general de determinar los presupuestos que afectan el patrimonio.

\section{Categoría 2: Pérdida del Patrimonio} Sub Categoría Medidas Coercitivas Reales: Pregunta iLa pérdida de patrimonio afecta los derechos fundamentales y patrimoniales ante el delito de lavado de activos? ¿Por qué?

\begin{tabular}{|c|l|}
\hline Experto & \multicolumn{1}{|c|}{ Respuesta derechos } \\
\hline Sáenz & $\begin{array}{l}\text { Los } \\
\text { fundamentales son aquellos } \\
\text { inseparables a la persona en } \\
\text { razón de su dignidad, que } \\
\text { no pueden estar vinculados } \\
\text { de ninguna manera con el } \\
\text { patrimonio de una persona } \\
\text { por tanto no puede existir } \\
\text { afectación. }\end{array}$ \\
\hline \multirow{3}{*}{ Garavito } & $\begin{array}{l}\text { La pérdida de patrimonio si } \\
\text { afecta los derechos } \\
\text { patrimoniales que conlleva } \\
\text { aúna afectación a los } \\
\text { derechos fundamentales }\end{array}$ \\
\hline \multirow{2}{*}{ García } & $\begin{array}{l}\text { Si, recordemos que estos } \\
\text { derechos son inherentes a la } \\
\text { persona por lo que también } \\
\text { es un derecho fundamental, } \\
\text { ante el delito de lavar } \\
\text { activos se pierde este } \\
\text { derecho porque el } \\
\text { patrimonio ha sido } \\
\text { adquirido de manera ilícita }\end{array}$ \\
\hline
\end{tabular}

\begin{tabular}{|c|c|}
\hline $\begin{array}{c}\text { Corvacho } \\
2019\end{array}$ & $\begin{array}{l}\text { La pérdida de un } \\
\text { patrimonio si afecta los } \\
\text { derechos fundamentales, } \\
\text { estos se pierden ante este } \\
\text { delito siempre y cuando se } \\
\text { demuestre que fue } \\
\text { adquirido de manera ilícita, } \\
\text { pero si esto no es } \\
\text { demostrado entonces habría } \\
\text { una desproporcionalidad de } \\
\text { parte del estado. }\end{array}$ \\
\hline $\begin{array}{c}\text { Coaquira } \\
2019\end{array}$ & $\begin{array}{l}\text { No, se trata de un proceso } \\
\text { mediante el cual se } \\
\text { convierte, transforma, } \\
\text { oculta dinero, bienes, } \\
\text { efectos o ganancias de } \\
\text { origen ilícito, por tanto, no } \\
\text { se puede afirmar que este } \\
\text { delito transgrede el derecho } \\
\text { de Propiedad. }\end{array}$ \\
\hline $\begin{array}{l}\text { Muñoz } \\
2019\end{array}$ & 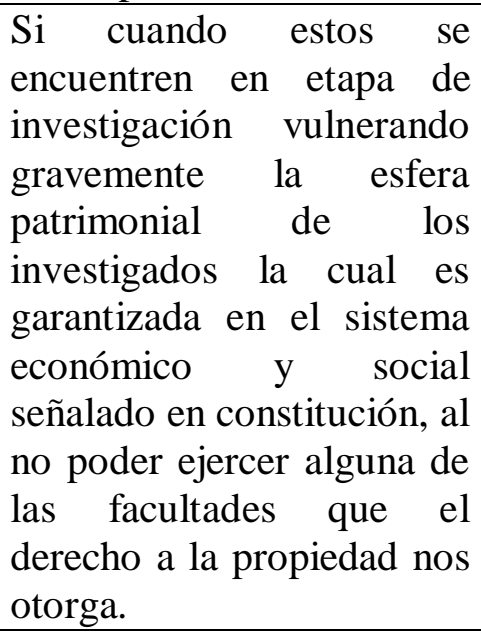 \\
\hline $\begin{array}{l}\text { Estela } \\
2019\end{array}$ & $\begin{array}{l}\text { Sí, porque este derecho está } \\
\text { expuesto ante el delito, ya } \\
\text { que la fiscalía ante una } \\
\text { investigación puede quitar } \\
\text { este derecho sin antes } \\
\text { comprobar o corroborar } \\
\text { que el patrimonio obtenido } \\
\text { es de procedencia licita o } \\
\text { ilícita }\end{array}$ \\
\hline
\end{tabular}

Fuente y elaboración: Propia

La gran mayoría de entrevistados coinciden en que la pérdida de un patrimonio si perjudica los derechos fundamentales y patrimoniales afectándose ante un delito de Lavado de Activos, sin 
embargo, la minoría de expertos como Sáenz y Coaquira señalan que no pueden estar vinculados por lo que no existe afectación alguna, por lo que no se puede afirmar que el delito de Lavado de Activos trasgreda el derecho de propiedad.

Se debe señalar que en el Acuerdo Plenario $\mathrm{N}^{\circ}$ 7-2011/CJ-116 se indica que las medidas de coerción reales, son sucesos, escritos en una resolución judicial, regida por el principio dispositivo, en donde se busca garantizar el resultado económico. Asimismo, el Decreto Legislativo $N^{\circ} 1106$ en su art. 9 señala que la incautación sobre los bienes que han sido adquiridos con recursos ilícitos, se aplica para asegurar el pago de la reparación civil y asegurar la sanción penal en el aspecto patrimonial del lavador, se debe señalar también que dentro de las medidas coercitivas reales, Cáceres (2017) refiere que estas medias de coerción real tienen como fin mantener y custodiar el bien del investigado o imputado, como también la del tercero civil, si en la investigación fiscal se detecta la responsabilidad de que los bienes inmuebles han sido adquiridos con dinero ilícito, tendrá que ser demostrado ante un juicio y su resultado será una sentencia firme y condenatoria.

Kleemans (2015) refiere que las incautaciones son de vital importancia dado que al activar esta medida coercitiva, le da la oportunidad al Estado a tener un seguro con una probabilidad del $90 \%$ a favor del Estado, siempre y cuando estas sean licitas y no perjudiquen a un tercero y si lo hiciesen se estaría vulnerando el derecho a la persona. Vega (2017) señala que esta medida coercitiva real tiene el propósito de recobrar aquello bienes que han sido comprados por activos ilícitos y están dentro de la economía nacional como lícitos, una vez recobrados bajo sentencia firme el Estado dispondrá y administrará los bienes, siempre y cuando no se afecte a terceros a engañados.
Pregunta 2 ¿El uso de las medidas coercitivas reales se viene llevando conforme a la norma? ¿Por qué?

\begin{tabular}{|c|c|}
\hline Experto & Respuesta \\
\hline Sáenz 2019 & $\begin{array}{l}\text { Las medidas de coerción } \\
\text { real recaen sobre el } \\
\text { patrimonio de un imputado } \\
\text { o sus bienes jurídicos } \\
\text { patrimoniales que se } \\
\text { encuentren regulados en el } \\
\text { C.P.P. y la Jurisprudencia } \\
\text { emitida a través de } \\
\text { diversos acuerdos } \\
\text { plenarios y casaciones por } \\
\text { lo que se vienen aplicando } \\
\text { conforme la normativa } \\
\text { vigente. }\end{array}$ \\
\hline $\begin{array}{c}\text { Garavito } \\
2019\end{array}$ & $\begin{array}{l}\text { Sí, se están llevando } \\
\text { conforme a la norma, } \\
\text { aunque cada caso es } \\
\text { diferente. }\end{array}$ \\
\hline $\begin{array}{l}\text { García } \\
2019\end{array}$ & $\begin{array}{l}\text { Sí, se viene llevando } \\
\text { conforme a la norma, pero } \\
\text { depende también de los } \\
\text { casos que se presentan a } \\
\text { veces son necesarias } \\
\text { aplicarlos de manera } \\
\text { rápida, para que el } \\
\text { investigado no pueda } \\
\text { traspasarlo a otro nombre. }\end{array}$ \\
\hline $\begin{array}{c}\text { Corvacho } \\
2019\end{array}$ & $\begin{array}{l}\text { La gran mayoría se viene } \\
\text { llevando conforme a la } \\
\text { norma, pero a veces es } \\
\text { necesario la actuación } \\
\text { pronta de la fiscalía por los } \\
\text { distintos casos que se } \\
\text { presentan, por lo que el } \\
\text { juez es el que da la orden } \\
\text { para poder usar estas } \\
\text { medidas y es la fiscalía la } \\
\text { que lo propone. }\end{array}$ \\
\hline $\begin{array}{c}\text { Coaquira } \\
2019\end{array}$ & $\begin{array}{l}\text { Sí, las medidas reales que } \\
\text { mayor uso se dan en este } \\
\text { delito son la incautación e } \\
\text { inhibición, los mismos que } \\
\text { se requieren ante el juez de }\end{array}$ \\
\hline
\end{tabular}




\begin{tabular}{|c|l|}
\hline & $\begin{array}{l}\text { investigación preparatoria } \\
\text { en caso cumpla con los } \\
\text { presupuestos y estos } \\
\text { recaigan en los bienes } \\
\text { relacionados }\end{array}$ \\
\hline \multirow{3}{*}{ Muñoz } & $\begin{array}{l}\text { Sí sobre todo las } \\
\text { incautaciones y los } \\
\text { embargos atendiendo que } \\
\text { solo con una resolución } \\
\text { motivada del juez es } \\
\text { posible su aplicación }\end{array}$ \\
\hline \multirow{3}{*}{ Estela 2019 } & $\begin{array}{l}\text { No, porque primero la } \\
\text { fiscalía debería tener al } \\
\text { menos una sospecha con } \\
\text { cierto grado de certeza y } \\
\text { no realizar incautaciones } \\
\text { por sospecha simple, ya } \\
\text { que esto contradice la } \\
\text { norma procesal. }\end{array}$ \\
\hline
\end{tabular}

Fuente y elaboración: Propia

La mayoría de entrevistados coinciden que si se viene llevando el uso de medidas coercitivas reales según lo indica la norma, no obstante para García y Corvacho depende de los casos que se presentan, pero la Fiscalía pueden usar este tipo de medidas coercitivas sin tener una imputación previa. Coaquira y Muñoz señalan que las medidas aplicadas son la incautación, embargo, inhibición, que se requieren ante el juez, muy por el contrario Estela señala que no se vienen llevando conforme a la norma dado que la Fiscalía no tiene una sospecha con grado de certeza pero al aplicar incautaciones por sospecha simple, esta contradice la norma penal.

Garavito, García, Corvacho, Muñoz, Estela, señalan que hay una afectación en los derechos patrimoniales de los investigados por el Delito de Lavado de Activos, sin embargo las medidas coercitivas reales para los entrevistados García y Corvacho se vienen llevando conforme a la norma dependiendo los casos que se presentan y se debe actuar de manera rápida, por lo que se infiere que este tipo de medida coercitivas puede utilizarse sin tener una imputación previa; asimismo Estela refiere que no se vienen llevando conforme a la norma dado que la Fiscalía no tiene una sospecha con grado de certeza, y que aplican incautaciones por sospecha simple, contradiciendo la norma penal, por lo que tiene similitud con lo que refieren García y Corvacho, de que este tipo de medidas coercitivas puede utilizarse sin tener una imputación previa; Senz y Garavito indican que dentro del proceso de Lavado de Activos se viene respetando el derecho del investigado; para Coaquira, Muñoz y Estela los derechos del investigado no se vienen respetando ya que los investigados y los terceros tienen diferentes mecanismos de defensa, al igual que todo pedido ante el juez debe ser motivado, y adjuntando elementos de cargo y sobre todo tener una imputación necesaria sin eso no puede realizarse una investigación y mucho menos una incautación.

Las investigaciones científicas internacionales, señalan que en este tipo de medida no puede perjudicar al tercero y si lo hace se estaría violentando su derecho, por lo que se concuerda con los entrevistados en que no se viene respetando los derechos del investigado así sea de buena fe o no y que las incautaciones se vienen llevando de manera irregular por presunción del delito, atentando así la presunción de inocencia y el derecho fundamental del patrimonio el cual está tipificado en nuestra Constitución que a través del art $\mathrm{n}^{\circ} 2$ inc. 16 señala el derecho a la propiedad, en concordancia con el art $\mathrm{n}^{\circ} 70$ en donde refiere que el estado garantiza la propiedad de una persona, esta solo será retenida a través de una medida cautelar siempre y cuando se demuestre el delito previo al igual que una imputación concreta.

Pregunta 3 ¿En el proceso de incautación en las investigaciones por el delito de 
lavado de activos se viene respetando derechos del investigado? ¿Por qué?

\begin{tabular}{|c|c|}
\hline Experto & Respuesta \\
\hline Sáenz 2019 & $\begin{array}{l}\text { Sí, porque para la } \\
\text { tramitación de una medida } \\
\text { cautelar de incautación se } \\
\text { efectúe a través de una } \\
\text { orden judicial. }\end{array}$ \\
\hline $\begin{array}{c}\text { Garavito } \\
2019\end{array}$ & $\begin{array}{l}\text { Sí, en la medida de lo } \\
\text { posible los derechos del } \\
\text { investigado. }\end{array}$ \\
\hline $\begin{array}{c}\text { García } \\
2019\end{array}$ & $\begin{array}{l}\text { Sí, en la medida de lo } \\
\text { posible, dependerá del } \\
\text { investigado demostrar lo } \\
\text { contrario. }\end{array}$ \\
\hline $\begin{array}{c}\text { Corvacho } \\
2019\end{array}$ & $\begin{array}{l}\text { Sí, pero a veces hay casos } \\
\text { en que la medida ha } \\
\text { afectado a investigados } \\
\text { que no han sido participes } \\
\text { de este tipo de delito por lo } \\
\text { que se afecta su derecho de } \\
\text { propiedad }\end{array}$ \\
\hline $\begin{array}{c}\text { Coaquira } \\
2019\end{array}$ & $\begin{array}{l}\text { No, el investigado y /o } \\
\text { tercero tienen diferente } \\
\text { mecanismo para hacer } \\
\text { prevalecer su derecho de } \\
\text { propiedad de ser } \\
\text { vulnerado, el cual está } \\
\text { considerado en el art } 222^{\circ} \\
\text { del C.P.P permite devolver } \\
\text { lo incautado }\end{array}$ \\
\hline $\begin{array}{l}\text { Muñoz } \\
2019\end{array}$ & $\begin{array}{l}\text { No, porque el pedido ante } \\
\text { el juez se realiza } \\
\text { debidamente motivado y } \\
\text { adjuntando los elementos } \\
\text { de cargo para que se } \\
\text { evalúen en el juzgado y se } \\
\text { emita la Orden Judicial } \\
\text { conforme a Ley, no } \\
\text { realizando lo de forme } \\
\text { inesperada. }\end{array}$ \\
\hline Estela 2019 & $\begin{array}{l}\text { No, porque primero debe } \\
\text { haber al menos una } \\
\text { imputación necesaria, sin } \\
\text { eso no puede realizarse } \\
\text { una investigación y mucho }\end{array}$ \\
\hline
\end{tabular}

\begin{tabular}{|l|l|}
\hline & $\begin{array}{l}\text { menos una incautación así } \\
\text { sea por lavar activos. }\end{array}$ \\
\hline
\end{tabular}

Fuente y elaboración propia

Aquí hay opiniones divergentes, para el Ministerio Publico de la Fiscalía Superior concuerdan que si se vienen respetando los derechos del investigado ante el proceso de incautación por lavar activos, mientras los de la Fiscalía Supraprovincial señalan que si se viene respetando pero que dependerá el investigado demostrar lo contrario, y que si afecta a los investigados que tal vez no tengan participación alguna y al realizar la medida de incautación afecta su derecho a la propiedad, para los especialistas en defensa concuerdan que no se respeta los derechos del investigado, ya que los investigados y los terceros tienen diferentes mecanismos de defensa, al igual que todo pedido ante el juez debe ser motivado, adjuntando elementos de cargo y tener una imputación necesaria, sin eso no puede realizarse una investigación y mucho menos una incautación.

\section{Categoría 3: Administración del Patrimonio}

Pregunta ¿Cuáles son los presupuestos para la ejecución de perdida de dominio ante el delito de lavado de activos? y ¿Cuál es el ente que lo administra?

\begin{tabular}{|l|l|}
\hline Experto & \multicolumn{1}{|c|}{ Respuesta } \\
\hline & $\begin{array}{l}\text { En nuestra actualidad } \\
\text { hablamos de la extinción } \\
\text { de dominio que se } \\
\text { encuentra regulado en el } \\
\text { Dáenz 2019 } \\
\text { proceso especial mediante } \\
\text { el cual el Estado declara la } \\
\text { pérdida del derecho de } \\
\text { propiedades que ha sido } \\
\text { producto de actividades } \\
\text { ilícitas, teniendo a cargo la } \\
\text { administración } \\
\text { PRONABI. }\end{array}$ \\
\hline
\end{tabular}




\begin{tabular}{|c|c|}
\hline $\begin{array}{c}\text { Garavito } \\
2019\end{array}$ & $\begin{array}{l}\text { Para la ejecución de un } \\
\text { proceso de perdida de } \\
\text { dominio es la medida que } \\
\text { recae sobre todo bien que } \\
\text { provenga o tenga origen } \\
\text { ilícito. }\end{array}$ \\
\hline $\begin{array}{c}\text { García } \\
2019\end{array}$ & $\begin{array}{l}\text { Los presupuestos están en } \\
\text { el art } \mathrm{n}^{\circ} 7 \text { del D. Leg. } 1373 \\
\text { solo son aplicables en el } \\
\text { delito de Lavado de } \\
\text { Activos, el PRONABI es } \\
\text { el ente que lo Administra. }\end{array}$ \\
\hline $\begin{array}{c}\text { Corvacho } \\
2019\end{array}$ & $\begin{array}{l}\text { Los presupuestos son: } \\
\text { objeto, } \\
\text { efectos o } \begin{array}{r}\text { instrumento, } \\
\text { ganancias }\end{array} \\
\text { ilícitas, } \\
\text { patrimonial no justificado, } \\
\text { bienes de procedencia } \\
\text { ilícita, } \\
\text { abandonados. } \\
\text { El ente que lo administra } \\
\text { es el PRONABI. }\end{array}$ \\
\hline $\begin{array}{c}\text { Coaquira } \\
2019\end{array}$ & $\begin{array}{l}\text { Los presupuestos para } \\
\text { procedencia de extinción } \\
\text { de dominio se encuentran } \\
\text { en el Art } 7 \text { del D. } \\
\text { Leg.1373, siendo aplicable } \\
\text { en el caso de delito de } \\
\text { Lavado de Activos } \\
\text { conforme lo establece el } \\
\text { Art } \mathrm{N}^{\circ} 01 \text { del mismo } \\
\text { cuerpo Normativo, quien } \\
\text { administra los bienes } \\
\text { incautados es el } \\
\text { PRONABI. }\end{array}$ \\
\hline $\begin{array}{l}\text { Muñoz } \\
2019\end{array}$ & $\begin{array}{l}\text { Actualmente la perdida de } \\
\text { domino es la extinción de } \\
\text { dominio y sus } \\
\text { presupuestos son } 7 \text { objeto, } \\
\text { instrumento, efectos o } \\
\text { ganancias ilícitas, } \\
\text { incremento patrimonial no } \\
\text { justificado, bienes de } \\
\text { procedencia ilícita, bienes } \\
\text { abandonados. }\end{array}$ \\
\hline Estela 2019 & $\begin{array}{l}\text { La pérdida de dominio está } \\
\text { tipificada en el D.Leg. } \\
1373 \text { y tiene como ente }\end{array}$ \\
\hline
\end{tabular}

\begin{tabular}{|l|lr|}
\hline & rector el art $\mathrm{n}^{\circ} \quad 7$ del \\
presente & Decreto \\
legislativo, además quien \\
vela y administra los \\
bienes incautados es el \\
PRONABI.
\end{tabular}

Fuente y elaboración: Propia

En este punto los entrevistados han coincidido que los presupuestos para dar la ejecución de pérdida o extinción de dominio están tipificados en el art 7 del D. Leg. 1373, los cuales son: objeto, instrumento, efectos o ganancias ilícitas, incremento patrimonial no justificado, bienes de procedencia ilícita, bienes abandonados y quien administra los bienes incautados es el PRONABI entidad que se encarga de administrar, preservar, mantener aquellos bienes que han sido incautados por actividades ilícitas como es el delito en estudio.

Keesoony (2016) refiere que en las leyes internacionales, para recobrar los bienes, son severas, porque estamos ante un delito internacional, sin embargo, Álvarez (2018) indica que en la Corte Colombiana se estableció que la extinción de dominio es un acto constitucional, ya que al identificar bienes muebles o inmuebles adquiridos con dinero ilícito de tráfico de influencias, narcotráfico, lavado de activos, etc. en perjuicio de la economía nacional y de la sociedad, entonces la extinción debe ser inmediata.

En este caso se concuerda con los artículos científicos internacionales, así como con los entrevistados, dado que los presupuestos establecidos en la normativa de extinción de dominio son claros, ya que debe existir un fundamento legal para realizarlos, así como la administración de estos bienes que se da ante el PRONABI, entidad que se encarga en cuidar y administrar el bien incautado. 
Sub Categoría Extinción de Dominio: ¿Cuándo se realiza la extinción de dominio? y ¿Cómo?

\begin{tabular}{|c|c|}
\hline Experto & Respuesta \\
\hline Sáenz 2019 & $\begin{array}{l}\text { Los presupuestos de } \\
\text { procedencia para la } \\
\text { realización del proceso de } \\
\text { extinción de dominio, se } \\
\text { encuentra regulado en el } \\
\text { art } N^{\circ} 7 \text { del D. Leg } 1373 \text {. }\end{array}$ \\
\hline $\begin{array}{c}\text { Garavito } \\
2019\end{array}$ & $\begin{array}{l}\text { La extinción de Dominio } \\
\text { es la nomenclatura que } \\
\text { hoy recibe hoy recibe el } \\
\text { proceso de Perdida de } \\
\text { Dominio }\end{array}$ \\
\hline $\begin{array}{c}\text { García } \\
2019\end{array}$ & $\begin{array}{l}\text { Esto se realiza siempre y } \\
\text { cuando se cuente con todos } \\
\text { los presupuestos que están } \\
\text { en la norma sino están } \\
\text { alguno de ellos se estaría } \\
\text { infringiendo en el derecho } \\
\text { del investigado. }\end{array}$ \\
\hline $\begin{array}{c}\text { Corvacho } \\
2019\end{array}$ & $\begin{array}{l}\text { La extinción se realiza con } \\
\text { el cumplimiento de la } \\
\text { norma si esta llegara a } \\
\text { infringirse el investigado } \\
\text { sufriría una mala praxis de } \\
\text { parte de la fiscalía. }\end{array}$ \\
\hline $\begin{array}{c}\text { Coaquira } \\
2019\end{array}$ & $\begin{array}{l}\text { Cuando cumpla los } \\
\text { presupuestos establecidos } \\
\text { en el Art } 7 \text { del D. Leg } 137 \text {, } \\
\text { el Ministerio Público } \\
\text { presenta una demanda ante } \\
\text { el juzgado penal } \\
\text { competente a fin de que } \\
\text { inicie un proceso de } \\
\text { extinción de dominio el } \\
\text { mismo que concluye con } \\
\text { una sentencia. }\end{array}$ \\
\hline $\begin{array}{c}\text { Muñoz } \\
2019\end{array}$ & $\begin{array}{l}\text { Enajenación o permuta de } \\
\text { otros bienes que } \\
\text { provengan de actos } \\
\text { ilícitos, bienes ilícitos que } \\
\text { no hayan sido objeto de } \\
\text { investigación, bienes de }\end{array}$ \\
\hline
\end{tabular}

\begin{tabular}{|c|c|}
\hline & $\begin{array}{l}\text { sucesión por causa de } \\
\text { muerte y que se encuentren } \\
\text { en cualquier de los } \\
\text { presupuestos anteriores. }\end{array}$ \\
\hline Estela 2019 & $\begin{array}{l}\text { Cuando tenga los } \\
\text { presupuestos descritos en } \\
\text { el art } n^{\circ} 7 \text { en la norma de } \\
\text { Extinción de Dominio, es } \\
\text { el Ministerio Público el } \\
\text { que ante demanda al } \\
\text { juzgado competente el que } \\
\text { decide se inicie el proceso } \\
\text { de extinción de dominio. }\end{array}$ \\
\hline
\end{tabular}

Fuente y elaboración: Propia

En este punto, los entrevistados han coincidido que la extinción de dominio se realiza de acuerdo con lo indicado a la norma la cual está tipificada en el D. Leg. 1373, los cuales son: Enajenación o permuta de otros bienes que provengan de actos ilícitos, bienes ilícitos que no hayan sido objeto de investigación, bienes de sucesión por causa de muerte asimismo Tanto García como Corvacho señalan que estos presupuestos tienen que cumplirse sino se estaría infringiendo la norma y el perjudicado seria el investigado, es el Ministerio Publico el que se encarga de interponer la extinción de dominio y es el Juzgado el que se encarga de sentenciar o no.

\section{Categoría 4: Destino del bien}

Sub Categoría: Reparación Civil y Beneficio del Estado: Ud. considera que ¿la incautación sirve para realizar una futura reparación civil? y ¿en qué beneficiaría al Estado?

\begin{tabular}{|c|c|}
\hline Experto & Respuesta \\
\hline Sáenz 2019 & $\begin{array}{l}\text { Tiene la finalidad de } \\
\text { asegurar el cumplimiento } \\
\text { de su función específica, la } \\
\text { investigación de la verdad } \\
\text { y la actuación de la Ley } \\
\text { Penal; a diferencia del } \\
\text { decomiso que este } \\
\text { destinada }\end{array}$ \\
\hline
\end{tabular}




\begin{tabular}{|c|c|}
\hline & $\begin{array}{lll}\text { aseguramiento } & \text { de } & \text { la } \\
\text { reparación civil. } & & \end{array}$ \\
\hline $\begin{array}{l}\text { Garavito } \\
2019\end{array}$ & $\begin{array}{l}\text { Definitivamente } \\
\text { incautación es como una } \\
\text { medida de la caución real } \\
\text { sirve a fin de asegurar, más } \\
\text { que la reparación civil, es } \\
\text { reintegrar al Estado los } \\
\text { efectos de procedencia } \\
\text { ilícita }\end{array}$ \\
\hline $\begin{array}{l}\text { García } \\
2019\end{array}$ & $\begin{array}{l}\text { Sí, beneficia al estado } \\
\text { porque si se demuestra la } \\
\text { ilicitud de los bienes, estos } \\
\text { vienen a pasar a formar } \\
\text { parte de la reparación a la } \\
\text { economía del estado y de } \\
\text { esa manera se asegura que } \\
\text { haya una justa equidad en } \\
\text { las partes afectadas. }\end{array}$ \\
\hline $\begin{array}{l}\text { Corvacho } \\
2019\end{array}$ & $\begin{array}{l}\text { Sí, esta beneficia mucho al } \\
\text { país, porque se regresaría } \\
\text { al estado lo perdido, por } \\
\text { una actividad ilícita, } \\
\text { reparan al estado el daño } \\
\text { causado es como una } \\
\text { caución real. }\end{array}$ \\
\hline $\begin{array}{l}\text { Coaquira } \\
2019\end{array}$ & $\begin{array}{l}\text { No, la incautación es sobre } \\
\text { bienes relacionados al } \\
\text { delito no guarda relación } \\
\text { con la reparación civil. Sí, } \\
\text { evita el riesgo de } \\
\text { ocultamiento de bienes y } \\
\text { otros que obstaculizan la } \\
\text { averiguación de la verdad. }\end{array}$ \\
\hline $\begin{array}{l}\text { Muñoz } \\
2019\end{array}$ & $\begin{array}{l}\text { No, porque no es su } \\
\text { finalidad, distinto seria que } \\
\text { se dicte un embargo. }\end{array}$ \\
\hline Estela 2019 & $\begin{array}{l}\text { No, porque la incautación } \\
\text { solo es una medida } \\
\text { temporal y no repara solo } \\
\text { previene. }\end{array}$ \\
\hline
\end{tabular}

Fuente y elaboración: Propia

En este punto se han dividido las respuestas, para el Ministerio Público de la Fiscalía Superior y Supraprovincial de Lavado de Activos concuerdan con que la incautación sirve como una futura reparación civil, mientras para los Defensores Legales la incautación no es una reparación civil, solo es una medida temporal y no guarda relación con esta medida que es de índole provisional.

Dentro de nuestra normativa legal, la Ley $\mathrm{N}^{\circ}$ 30737 que en el artículo 2 señala que al Estado se le indemniza a través de sentencia firme por el delito contra la administración pública, lavado de activos o delitos conexos o equivalentes, delitos que deberán ser demostrados, a partir de la publicación de esta norma, nuestro país puede reclamar la reparación civil que corresponde en este tipo de delito complejo, por ello el compendio de normas dentro de este decreto legislativo ayudan a resarcir no solo al país, sino a toda la sociedad, asimismo las medidas para asegurar el pago de reparación civil por un delito de lavado de activos son: transferencias al exterior, adquisición y retención del Fideicomiso de Retención y Reparación. Retención de importes a favor del Estado, Anotación preventiva. Estas medidas asegurativas, ayudan a resarcir el daño causado al estado, asimismo la reparación civil se realiza para que la sociedad tenga justicia sobre el daño causado, al bien jurídico común protegido,

En este punto se han dividido las respuestas, para el Ministerio Público de la Fiscalía Superior y Supraprovincial de Lavado de Activos concuerdan con que la incautación sirve como una futura reparación civil, mientras para los Defensores Legales la incautación no es una reparación civil, solo es una medida temporal y no guarda relación con esta medida que es de índole provisional.

En los artículos científicos internacionales Kordík y Kurilovská (2017) señalan que el estado tiene que hacer una evaluación general de los hechos, para que de esa forma se conozca los riesgos y el alcance que ha tenido dentro y fuera del país, de esa forma se podrán optar medidas y saber el daño ocasionado, por ello es importante que el 
estado obtenga una reparación civil siempre y cuando esta sea por un delito comprobado.

Se concuerda con los artículos científicos internacionales y con los defensores legales ya que, si una persona es investigada por este delito y no se le ha corroborado el hecho ilícito, su bien no puede ser reparación civil, antes de ello se deberá comprobar el delito por el que se le está imputando, la reparación civil es devolver lo dañado a su estado original siempre y cuando se compruebe lo dañado.

\section{Categoría 5: Devolución del Patrimonio} Sub Categoría Variación de la Medida: Ud. Explique ¿Si la variación de la medida por el bien incautado se viene llevando de forma correcta ante un delito de lavado de activos?

\begin{tabular}{|c|c|}
\hline Experto & Respuesta \\
\hline Sáenz 2019 & $\begin{array}{l}\text { No precisa la pregunta qué } \\
\text { tipo de variación de } \\
\text { medida, ya que habla solo } \\
\text { de los bienes incautados, } \\
\text { pero indica porque otra } \\
\text { medida. }\end{array}$ \\
\hline $\begin{array}{l}\text { Garavito } \\
2019\end{array}$ & Sí. \\
\hline $\begin{array}{c}\text { García } \\
2019\end{array}$ & $\begin{array}{l}\text { Ante el nuevo código } \mathrm{Si} \text {, } \\
\text { en la medida que los } \\
\text { bienes sean de procedencia } \\
\text { ilícita pero hay una gran } \\
\text { grupo que aún tiene } \\
\text { problemas en realizar las } \\
\text { variantes de esta medida } \\
\text { dado que ante este delito es } \\
\text { un poco difícil. }\end{array}$ \\
\hline $\begin{array}{l}\text { Corvacho } \\
2019 \\
\end{array}$ & $\begin{array}{l}\text { Sí, se trata de seguir la } \\
\text { norma. }\end{array}$ \\
\hline $\begin{array}{l}\text { Coaquira } \\
2019\end{array}$ & $\begin{array}{l}\text { Respecto a la incautación } \\
\text { solo procede la devolución } \\
\text { que esta recae sobre los } \\
\text { bienes que guarda relación } \\
\text { con el delito de Lavado de } \\
\text { Activos, siempre y cuando } \\
\text { se varíen los presupuestos }\end{array}$ \\
\hline
\end{tabular}

\begin{tabular}{|c|l|}
\hline & $\begin{array}{l}\text { y se levante mediante la } \\
\text { resolución. }\end{array}$ \\
\hline Mú, puesto que si varían los \\
presupuestos r que \\
determinaron ra r a \\
imposición de la medida \\
de incautación, re \\
levantaran la medida a \\
pedido de Ministerio \\
$\begin{array}{l}\text { Publico o del Interesado } \\
\text { previa coordinación. }\end{array}$ \\
\hline Estela 2019 \\
$\begin{array}{l}\text { No, porque es muy } \\
\text { probable que suceda ya } \\
\text { que al presentar la } \\
\text { motivación requerida esta } \\
\text { tiende a ser descartada. }\end{array}$ \\
\hline
\end{tabular}

Fuente y elaboración: Propia

Los entrevistados de la Fiscalía superior indican que si se viene llevando de forma correcta la variación de medida, no obstante los entrevistados de la Fiscalía Supraprovincial como García señala que hay un grupo de incautaciones que tienen problemas para realizar la variante de la medida de incautación, Coaquira señala que siempre y cuando varíen los presupuestos se levanta la resolución al igual que Muñoz, pero Estela revela que es muy probable que la variación de medida no suceda, aunque esta esté motivada será descartada.

Sub Categoría: Reexamen de la Medida: Explique Ud. ¿Cuál es el procedimiento para realizar el reexamen de medida de un bien incautado ante el delito de lavado de activos?

\begin{tabular}{|c|l|}
\hline Experto & \multicolumn{1}{|c|}{ Respuesta } \\
\hline Sáenz 2019 & $\begin{array}{l}\text { Estas se encuentran } \\
\text { reguladas en lo establecido } \\
\text { en el Art 319 y 320 del } \\
\text { Código Procesal Penal }\end{array}$ \\
\hline Garavito & $\begin{array}{l}\text { La incautación recae sobre } \\
\text { los bienes de procedencia } \\
\text { ilícita y la medida del } \\
\text { reexamen opera cuando } \\
\text { existe un tercero de buena } \\
\text { fe en el proceso (ante los }\end{array}$ \\
\hline
\end{tabular}




\begin{tabular}{|c|c|}
\hline & $\begin{array}{l}\text { bienes incautados) siendo } \\
\text { estos terceros quienes } \\
\text { deberán acreditar ante la } \\
\text { autoridad su buena fe. }\end{array}$ \\
\hline $\begin{array}{l}\text { García } \\
2019\end{array}$ & $\begin{array}{l}\text { Solicitar el reexamen ante } \\
\text { el juez que emitió la } \\
\text { resolución de la medida } \\
\text { por los propietarios de } \\
\text { buena fe }\end{array}$ \\
\hline $\begin{array}{l}\text { Corvacho } \\
2019\end{array}$ & Se solicita ante el juez \\
\hline $\begin{array}{l}\text { Coaquira } \\
2019\end{array}$ & $\begin{array}{l}\text { Se solicita el reexamen } \\
\text { ante el juez que emitió la } \\
\text { solución de incautación } \\
\text { por los propietarios de } \\
\text { buena fe que no hayan } \\
\text { intervenido en el delito. }\end{array}$ \\
\hline $\begin{array}{l}\text { Muñoz } \\
2019\end{array}$ & $\begin{array}{l}\text { Solicitar la devolución al } \\
\text { ministerio Público las } \\
\text { personas consideradas } \\
\text { propietarios de buena fe y } \\
\text { que no han intervenido en } \\
\text { el delito Investigado, } \\
\text { podrán solicitar el } \\
\text { reexamen luego al juzgado } \\
\text { correspondiente para la } \\
\text { audiencia. }\end{array}$ \\
\hline Estela 2019 & $\begin{array}{l}\text { Se solicita al juez mediante } \\
\text { una debida motivación. }\end{array}$ \\
\hline
\end{tabular}

Fuente y elaboración: Propia

Los entrevistados concuerdan que se debe solicitar el reexamen de medida ante el Juez, el cual determinará si devuelve o no el bien incautado, es más el peticionario debe cumplir con el requisito de ser propietario de buena fe, lo que significa que deberá demostrarlo con las diferentes pruebas que acrediten la licitud de la adquisición del bien incautado.

La variación de la medida está establecida en nuestra normativa penal en el art 318 inciso 3 , el cual señala que si el bien incautado puede ser devuelto a cambio de un depósito, puede presentar una caución garantía real o cumpla determinadas condiciones, asimismo la variación de la medida puede darse en la etapa preparatoria, siempre y cuando demuestre que la medida ha lesionado las garantías constitucionales; sin embargo, Estela revela que es muy probable que la variación de medida no suceda, aunque esta esté motivada será descartada y esto es porque los casos emblemáticos tienden a tener una gran complejidad, por lo que la norma le favorece a los operadores del derecho ya que al ser delito autónomo y complejo no es necesario tener imputación fija ya que solo se presume el delito y este acarrea una investigación larga y tediosa por lo que la variación de medida no procede para todos.

Los entrevistados de la Fiscalía superior indican que si se viene llevando de forma correcta la variación de medida, Coaquira señala que siempre y cuando varíen los presupuestos se levanta la resolución al igual que Muñoz, no obstante García señala que hay un grupo de incautaciones que tienen problemas para realizar la variante de la medida de incautación, por lo que si la medida ha devenido de un tráfico de influencias para perjudicar al investigado, en este punto se pide la nulidad y la recusación del juez, así sea en el delito de lavado activos la variación de la medida puede darse, esta variación lo puede pedir el representante de la acción penal como también el interesado,

El reexamen al igual que la variación de la medida se realiza en la etapa preparatoria, y puede interponerlo aquel que pueda acreditar que el patrimonio incautado no ha sido adquirido con dinero ilícito, así como también el tercero de buena fe, esto criterio se puede observar en la Casación n. ${ }^{\circ}$ 6462014, Corte Suprema de Justicia de la República (2016), la cual establece que aquellas personas que se valoren como terceros de buena fe y son propietarios de aquellos bienes incautados y que no tienen relación alguna con el delito que está siendo investigado, podrán solicitar el reexamen de la medida de incautación, a fin que se les devuelva la propiedad incautada. 
Los entrevistados concuerdan que se debe solicitar el reexamen de medida ante el Juez, el cual determinará si devuelve o no el bien incautado, es más este debe cumplir con el requisito de ser propietario de buena fe, lo que significa que deberá demostrarlo con las diferentes pruebas que acrediten la licitud de la adquisición del bien incautado, no obstante esta variación y reexamen se realizará previa audiencia, en la cual estará el peticionario; de esa forma procede una variación o reexamen de la medida, pero estas precisiones difieren mucho en la realidad, dado que en el delito de lavado de activos, las variaciones de medida $o$ reexamen de medida siempre quedan anuladas, ya que el art. 10 del D. Leg. $\mathrm{N}^{\circ}$ 1106, señala que la Fiscalía presume el origen ilícito de los activos, amparado en la autonomía procesal, por lo que son los investigados los que deberán demostrar su inocencia, esta posición ha sido avalada por el Poder Judicial. (2017) en su Acuerdo Plenario Casatorio, el cual confirma que una vez que asuma presunción el fiscal, interpondrá las medidas pertinentes si así lo precisa; por lo que deja en una gran incertidumbre para aquellos que deseen realizar este tipo de mecanismo legal.

\section{CONCLUSIONES}

La afectación que sufre un investigado no solo es a nivel patrimonial, sino también de sus derechos fundamentales, que son trasgredidos por esta mala praxis ante la ausencia de otros mecanismos alternativos menos lesivos, que le permitan al investigado en cuanto se defina su situación jurídica, seguir en posesión y propiedad de sus bienes patrimoniales sin que sean afectados, permitiéndole mantener su estilo de vida, en este caso no solo del investigado sino también de su entorno familiar.

La incautación afecta el patrimonio del investigado, dado que a través de los delitos fuente de Lavado de Activos, como son la
Usurpación y la Estafa, hacen que las personas caigan ante este tipo de delito y al interponer el Estado a través de sus representantes, este tipo de medida sin tener una imputación concreta está violentando su derecho patrimonial, lo cual ha sido demostrado en los resultados de esta investigación.

Se ha determinado que la pérdida de dominio se da a través de las medidas coercitivas contra el patrimonio, una de ellas es la incautación, la cual tiene como ente administrativo el PRONABI, asimismo se ha demostrado con los resultados que la gran mayoría de casos no sigue los presupuestos normativos que se usan para realizar una incautación, dado que la Fiscalía no tiene una sospecha con grado de certeza, pese a lo cual solicita la incautación por sospecha simple perjudicando a los investigados o a los terceros.

El destino de los bienes incautados tienen como finalidad reparar el daño causado, no obstante aquel que crea que el bien adquirido fue de forma licita tendrá que probarlo, dado que ante un delito de alta complejidad no es fácil realizar la variación de la medida, esto contradice a la realidad nacional, dado que la gran mayoría de personas dueñas de bienes muebles, sobre todo en el interior del país no tienen una cultura registral como en la capital, por lo que a través de los resultados se señala que solo a través de pruebas el bien podrá ser devuelto, perjudicando así a aquel que de buena fe compró un bien inmueble sin tener un título, como lo que ocurrió en los caso Orellana, Palomino, Rever etc. dejando desprotegido al perjudicado.

Los presupuestos que afectan fundamentalmente el patrimonio de un investigado ante un caso en la Primera Fiscalía Supraprovincial de lavado de activos y pérdida de dominio son la afectación del patrimonio, pérdida del patrimonio, administración del patrimonio, 
destino del bien y devolución del patrimonio. Para ello la Fiscalía debe establecer los procedimientos de incautación de los bienes sin vulnerar los principios constitucionales referidos a la propiedad.

\section{FUENTES DE INFORMACIÓN}

\section{Fuentes bibliográficas:}

Calamandrei, P. (1986) Instituciones del derecho Procesal civil volumen I. Buenos Aires, Argentina: Ediciones jurídicas Europa.

Calix López, C; Zazueta Bastidas, L. y Macias Díaz, J. (2012) Metodología de la Investigación Cientifica 1. ( $5^{\circ} \mathrm{ed}$.). México, México: Editorial Once Ríos

Condorelli Epifanio, J.L. (1986). El Abuso Y La Mala Fe Dentro Del Proceso. Buenos Aires, Argentina: Abeledo- Perrot.

Chanjan, R, Solis Curi, E y Puchuri, F. (2018). Sistema de Justicia, Delitos de Corrupción y Lavado de Activos. Lima, Perú: Instituto de Democracia y Derechos Humanos de la Pontificia Universidad Católica del Perú.

Chiovenda, G. (1948). Instituciones Del Derecho Procesal Civil. Madrid, España: Derecho Privado.

Gálvez Villegas, T. ; Rabanal Palacios, W. ; Castro Trigozo, H.(2010). El Código Procesal Penal, Comentarios Descriptivos, Explicativos y Críticos. Lima, Perú: Jurista Editores E.I.R.L.

Gálvez Villegas, T. (2015). Decomiso, Incautación y Secuestro. $\left(2^{\circ}\right.$ ed.). Lima, Perú: Sur Grafica Editorial.

García Cavero, P. (2015) Derecho Penal Económico. Lima, Perú: Pacifico Editores
Gómez Bastar, S. (2012). Metodología de La investigación publicada. México, México: Red Tercer Milenio.

Hernández Sampieri, R. ; Fernández Collado, C. y Bapista Lucio, P. (2014). Metodología de la Investigación. ( $6^{\circ}$ ed.). México, México: Edamsa Impresiones, S.A.

Inegi. (2005), Curso de Metodología de la Investigación. México, México: Inegi

Monje Álvarez, C. (2011) Metodología de la Investigación Cuantitativa y Cualitativa, Guía Didáctica. Neiva, Colombia: Universidad Sur Colombiana

Pariona Pastrana, J. (2017). El Delito Precedente En El Delito De Lavado De Activos: Aspectos Sustantivos $Y$

Consecuencias Procesales. Lima, Perú: Instituto Pacific

Savona, E.; Riccardi, M.; Milani, R; Camerini, D.; Kleemans, E.; Ferwerda, J.; Hopkins, M. y Shelton, N (2017), Assessing the risk of money laundering in Europe. Final Report of Project IARM. Milano, Italy: Transcrime - Università Cattolica del Sacro Cuore.

Soleto Muñoz, H y Grané Chávez, A. (2019) La reparación económica a la víctima en el sistema de justicia. Madrid, España: Editorial Dykinson.

\section{Fuentes electrónicas:}

Ackerman, S. y Palifka, B. (2018) Corruption, Organized Crime, and Money Laundering. In: Basu K., Cordella T. (Eds) Institutions, Governance, and the Control of Corruption. International Economic Association Series. Palgrave Macmillan, Cham. 1(1). England. Recuperado de https://doi.org/10.1007/978-3-319-656847_4 
Acosta, K. (2016). Análisis del Art. 615 CPC: caso especial de procedencia de una medida cautelar tras la obtención de una sentencia favorable. (Tesis de pregrado). Universidad de Piura, Perú. Recuperado de https://pirhua.udep.edu.pe/bitstream/handle /11042/2358/DER_048.pdf?sequence=1

Acuerdo Plenario $\mathrm{N}^{\circ}$ 5-2010/CJ-166, fundamento: artículo $116^{\circ}$ TUO LOPJ, asunto: incautación, Corte Suprema de Justicia de la República, VI Pleno Jurisdiccional de las Salas Penales Permanente y Transitoria, 16 de noviembre de 2010 (Perú). Recuperado de URL:https://www.pj.gob.pe/wps/wcm/con nect/CorteSuprema/s_cortes_suprema_ho me/as poder judicial/as corte suprema/as _salas_supremas/as_sala_penal_permanent e/as_acuerdos_plenariosyentencias_vincul antes_spp/as_acuerdos $2010 /$

Anton Siancas, K. (2017) Regulación de los efectos procesales generados por la omisión de la confirmación de la incautación en el código procesal penal peruano (Tesis de Pregrado). Universidad Cesar Vallejo, Perú. Recuperado de http://repositorio.ucv.edu.pe/handle/UCV/1 6957

Ascencios, J (2018). La incautación inmobiliaria. Los efectos reales y formas jurídicas involucradas, apropósito de un caso. Recuperado de http://works.bepress.com/jorgeluis_ascenci osdavila/8/

Álvarez, H. (2018). Acción constitucional de extinción de dominio en Colombia. Nuevos Paradigmas De Las Ciencias Sociales Latinoamericanas. Recuperado de http://www.ilae.edu.co/Ilae_OjsRev/index. php/NPVol-VII-Nro14/article/view/241

Bajo, M. (2016). El uso de las tecnologías en la entrada y el registro domiciliario: cambio en su concepción tradicional y nuevos retos en la protección de derechos fundamentales.Recuperado de https://search.proquest.com/docview/1892 122103 ? accountid $=37408$.

Barone, R, Side, D, y Masciandaro,D. (2017). Drug trafficking, money laundering and the business cycle: Does secular stagnation include crime? Metroeconomica 47(69). Recuperado de http://dx.doi.org/10.2139/ssrn.2896012

Bidal, P. (2015). Seized and Forfeited Asset Management Project - BIDAL. Recuperado de

http://www.cicad.oas.org/Main/Template.a sp?File=/lavado_activos/bidal_eng.asp

Brenig, C, Accorsi, R, y Müller, G. (2015). Economic Analysis of Cryptocurrency Backed Money Laundering. Twenty-Third European Conference on Information Systems. (1). Germany. Recuperado de http://aisel.aisnet.org/ecis2015_cr/20

Bustamante, S, y Elizalde, L. (2016). La Inadecuada Imposición De Medidas Cautelares Reales a las Entidades Públicas en Juicios Laborales para Asegurar Cumplimiento De La Obligación. (Tesis de maestría) Unidad Académica De Ciencias Sociales, Ecuador. Recuperado de http://repositorio.utmachala.edu.ec/handle/ 48000/8126

Castillo, O. (2017) Vulneración de los derechos del imputado en relación a la demora del pedido de confirmatoria de incautación efectuado por fiscalías penales de Tarapoto, año 2015. (Tesis de Pregrado). Universidad Cesar Vallejo, Perú. Recuperado de http://repositorio.ucv.edu.pe/handle/UCV/1 6555

Castello, J y Segovia, J. (2015). Manual de prevención de lavado de activos y contra el financiamiento del terrorismo para microempresa de Guayaquil. (Tesis de 
Pregrado) Universidad Laica Vicente Rocafuerte De Guayaquil. Ecuador. Recuperado de http://repositorio.ulvr.edu.ec/handle/44000/ 730

Caro Coria, D. (2015) Lavado de Activos provenientes del Delito Tributario. Recuperado de http://revistas.pucp.edu.pe/index.php/iuset veritas/article/download/14816/15372

Cedano, V. (2017). Aplicación y relación de la ley de extinción de dominio con el delito de lavado de activos en el Distrito Fiscal de Piura. (Tesis Pregrado). Universidad de Piura. Perú. Recuperado de http://repositorio.unp.edu.pe/handle/UNP/1 526

Congreso de la República. (1993). Constitución Política del Perú. Recuperado de http://www.pcm.gob.pe/wpcontent/uploads/2013/09/ConstitucionPol\%C3\%ADtica-del-Peru-1993.pdf

Congreso de la Republica. (2012) D. L 1106 De Lucha Eficaz Contra El Lavado De Activos Y Otros Delitos Relacionados A La Minería Ilegal Y Crimen Organizado. Recuperado de https://busquedas.elperuano.pe/normaslega les/decreto-legislativo-de-lucha-eficazcontra-el-lavado-activos-decretolegislativo-n-1106-778570-3 /

Congreso de la Republica. (2018) Decreto Legislativo 30737. Ley que asegura el pago inmediato de la Reparación Civil a favor del Estado Peruano en casos de Corrupción y Delitos Conexos. Recuperado de https://busquedas.elperuano.pe/download/u r1/ley-que-asegura-el-pago-inmediato-dela-reparacion-civil-a-f-ley-n-307371624757-1

Corte Suprema de Justicia (2011) Delito De Lavado De Activos y Medidas De Coerción Reales. Refiere el Acuerdo Plenario $N^{\circ} 7$ -
2011/CJ-116. Recuperado de https://www.pj.gob.pe/wps/wcm/connect/9 62d97004075b5c8b422f499ab657107/AC UERDO+PLENARIO+N\%C2\%B0+7011. pdf?MOD $=$ AJPERES\&CACHEID $=962 \mathrm{~d} 9$ $7004075 b 5 c 8 b 422 f 499 a b 657107$

Corte Suprema de Justicia (2016) Sala Penal Permanente Casación N. ${ }^{\circ}$ 646-2014 Sullana Recuperado de https://www.pj.gob.pe/wps/wcm/connect/8 217da004389bae782e3ceb286bd5fbb/CAS $+6462014+$ Sullana.pdf?MOD=AJPERES $\&$ CACHEID $=8217 \mathrm{da} 004389 \mathrm{bae} 782 \mathrm{e} 3 \mathrm{ceb}$ 286bd5fb

Corte Suprema de Justicia de Costa Rica (2018) Exp001143-2010 - División Jurídica. Recuperado de URL:https://cgrfiles.cgr.go.cr/publico/docs _cgr/2018/SIGYD_D_2018015274.pdf

Corte Suprema de Justicia (2018) Sala Penal Permanente, Recurso Casación N. ${ }^{\circ}$ 864-2017. Recuperado de http://www.gacetajuridica.com.pe/boletinnvnet/ar-web/cas864-2017-Nacional.pdf

Chávez, V y Castillo, K. (2015) Plazo legal para la liquidación de costos y costas en un proceso Ejecutivo con embargo sobre derechos de crédito ejecutada. Avances Revista de Investigación Jurídica. 10(12). 145 - 155. Perú. Recuperado de http://www.revistas.upagu.edu.pe/index.ph $\mathrm{p} / \mathrm{AV} /$ article/view/175/126

Chiriac, L, y Blaj, S. (2018). The Philosophy of the Society Rights in the Application of Penalties in Implementing the Criminal Law. Juridical Current, 21(2), 87-94. Recuperado de http://search.ebscohost.com/login.aspx?dir ect $=$ true $\& d b=a 9 h \& A N=130469287$ \&lang $=$ es $\&$ site $=$ eds-live.

Congreso de la República. (2019) Decreto Legislativo 1373. Decreto Legislativo de Extinción de Dominio. Recuperado de 
https://busquedas.elperuano.pe/normaslega les/decreto-legislativo-sobre-extincion-dedominio-decreto-legislativo-n-1373$1677448-2 /$

Escamilla, R. (2017) Problemática en la aplicación práctica de la figura de extinción de dominio en materia federal en México. (Tesis de Pre grado).Universidad Panamericana, México. Recuperado de http://biblio.upmx.mx/tesis/157807.pdf

Garay Mercado, M. (2013). Requerimientos de confirmación de incautacion en caso de intervenciones en delitos flagrantes. Recuperado de https://doi.org/10.31381/inkarri.v0i2.79

García Cavero, P (2018) El decomiso de bienes relacionados con el delito en la legislación penal peruana. Recuperado de http://dx.doi.org/10.18800/derechopucp.20 1802.004

Higa, C. (2013) El Derecho a la Presunción de Inocencia desde un punto de Vista Constitucional. Recuperado de http://revistas.pucp.edu.pe/index.php/derec ho ysociedad/article/viewFile/12793/13350

Keesoony, S. (2016). International antimoney laundering laws: the problems with enforcement, Journal of Money Laundering Control. 19(2), pp.130 - 147. Recuperado de https://doi.org/10.1108/JMLC-06-20150025

Kordík, M y Kurilovská, L. (2017). Protection of the national financial system from the money laundering and terrorism financing, Entrepreneurship and Sustainability. 5(2). 243-262. Recuperado de https://doi.org/10.9770/jesi.2017.5.2(7)

Kleemans, E. (2015). Follow the Money. Introduction to the Special Issue 'Financial Aspects of Organized Crime. European Journal on Criminal Policy and Research, 21(2), 213-216.Amsterdam. Recuperado dehttps://doi.org/10.1007/s10610-0159279-5

Legis.pe (2018) La presunción de inocencia y las paradojas de nuestro sistema procesal. Lima: Ramos, L. Recuperado de https://legis.pe/presuncion-inocenciaparadojas-nuestro sistema-procesal/

Martínez, J. (2016) La Vulneración del Principio de Imputación Necesaria en las Disposiciones Fiscales de Formalización de Investigación Preparatoria (Tesis de Maestría). Universidad de Nacional de Trujillo, Perú. Recuperado de http://dspace.unitru.edu.pe/handle/UNITR $\mathrm{U} / 7964$

Martínez, J. (2017) El delito de blanqueo de capitales. (Tesis de Doctorado) Universidad Complutense De Madrid, España. Recuperado de https://eprints.ucm.es/41080/1/T38338.pdf

Mera, L. (2018). La medida cautelar innecesaria o maliciosa (Tesis de Maestría). Universidad Federico Villareal, Perú. Recuperado de http://repositorio.unfv.edu.pe/handle/UNF $\mathrm{V} / 2052$

Middleton, D y Levi, M. (2015). Let Sleeping Lawyers Lie: Organized Crime, Lawyers and the Regulation of Legal Services. The British Journal of Criminology, 55(4) 647-668. England. Recuperado de https://doi.org/10.1093/bjc/azv001

Navarrete, N. (2018). El tipo subjetivo en los delitos de lavado de activos: situación del dolo eventual en el delito del Artículo 27 letra a) de la Ley 19.913 (Tesis de Pregrado). Universidad de Chile, Chile. Recuperado de http://repositorio.uchile.cl/handle/2250/153 080

OAS. (1978). Convention On Human Rights Pact Of San Jose, Costa Rica. 
Recuperado

de

https://www.oas.org/dil/access_to_informa tion_American_Convention_on_ights.pdf

ONU. (2019) Human Rights and Rights of the person. Recuperado de https://www.un.org/en/sections/uncharter/introductory-note/index.html

Offiong. D, y Agbaji, D. (2017) The Pursuit of Good Governance and the Anti-Financial Corruption Blitz in Nigeria: A Study of the Economic and Financial Crimes Commission (EFCC) (2003-2016). Asian Research Journal of Arts \& Social Sciences, 2(4), 1-16. Recuperado de https://doi.org/10.9734/ARJASS/2017/321 15

Poder Judicial. (2017). I Pleno Casatorio Penal de la Corte Suprema de Justicia de la República., Sentencia Plenaria Casatoria. Recuperado de http://perso.unifr.ch/derechopenal/assets/fil es/jurisprudencia/j_20171208_01.pdf

Poder Judicial. (2018). Incautación Cautelar de bienes muebles e inmuebles y productos bancarios y otros. Exp.249-2015$40 . \quad$ Recuperado de https://www.pj.gob.pe/wps/wcm/connect/c 411708048e56d22aa16ee0375cdf40c/Exp. +249 -

015SPANincautacion + Caso $+\mathrm{OH}+\mathrm{y}+\mathrm{NH} . \mathrm{p}$ $\mathrm{df} ? \mathrm{MOD}=\mathrm{AJPERES} \& \mathrm{CACHEID}$

Poder Judicial (2018) Corte Superior De Justicia De Lima. Medidas Cautelares. EXP 0011-2017-43-1801-SP-CI-01. Recuperado de

http://educared.fundaciontelefonica.com.pe /desafioseducacion/wpContent/uploads/site s/2/2018/03/Medida-cautelar-Corte-

Superior-de-Justicia-de-Lima.pdf

Poder Judicial Argentino. (2018). Cámara Nacional de Apelaciones en lo Criminal y Correccional - Exp46940 - 2011 - CA4 Sala 5. Recuperado de http://www.pensamientopenal.com.ar/syste $\mathrm{m} /$ files/2018/11/fallos47177.pdf

Poder Judicial Argentino. (2018). Cámara Nacional de Apelaciones en lo Criminal y Correccional - Exp46940 - 2011 - CA4 Sala 5. Recuperado de http://www.pensamientopenal.com.ar/syste $\mathrm{m} /$ files/2018/11/fallos47177.pdf

Ramos, C. (2017). Aplicación del principio de proporcionalidad en las resoluciones judiciales sobre medidas de incautación en la Provincia de Maynas 2013-2016. (Tesis de Maestría). Universidad Nacional de San Agustín de Arequipa. Perú. Recuperado de http://repositorio.unsa.edu.pe/handle/UNS A/5866

Roig Torres, M. (2016). La regulación del comiso. El modelo alemán y la reciente reforma española. Estudios Penales y Criminológicos, 36. Recuperado de www.usc.es/revistas/index.php/epc/article/ download/3028/3389

San Martin, C (2002). La tutela cautelar de las consecuencias jurídicas económicas del delito. Ius et veritas, $\mathrm{N}^{\circ} 25$, pág. $312-313$ Recuperado de http://revistas.pucp.edu.pe/index.php/iuset veritas/article/view/16217/16634

Santander, G. (2018). Naturaleza jurídica de la extinción de dominio: Fundamentos de las causales extintivas. (Tesis de Maestría). Universidad Santo Tomás En Convenio Con La Universidad De Salamanca, Colombia. Recuperado de http://dx.doi.org/10.15332/tg.mae.2018.00 168

Soudijn, M. (2019). Using Police Reports to Monitor Money Laundering Developments. Continuity and Change in 12 Years of Dutch Money Laundering Crime Pattern Analyses. European Journal on Criminal Policy and Research. 25(1). 83 - 97. Dutch. 
Recuperado

de

https://doi.org/10.1007/s10610-018-9379-0

Torres, M. (2018). La prueba Indiciaria en el delito de Lavado de Activos. (Tesis de Pregrado) Universidad del Azuay, Ecuador. Recuperado de http://dspace.uazuay.edu.ec/handle/datos/8 618

Umiyauri, P. (2016) La vulneración del debido proceso en la incautación y el registro del contenido de los teléfonos móviles en el distrito fiscal de Apurímac 2015-2016 (Tesis de Pregrado). Universidad Nacional San Agustín de Arequipa, Perú. Recuperado de http://repositorio.unsa.edu.pe/handle/UNS $\mathrm{A} / 2228$

UNAM. (2015). CORPUS JURIS CIVILES - CODEX JUSTINIANEI - DIGESTIUM. Recuperado de https://archivos.juridicas.unam.mx/www/bj v/libros/5/2311/4.pdf

UNCAC (2019) Conference of the States Parties to the United Nations Convention against Corruption. Recuperado de https://www.unodc.org/documents/treaties/ UNCAC/WorkingGroups/Implementation ReviewGroup/27-

29May2019/V1902843e.pdf

UNODC (2019) United Nations Convention Against Corruption, Office Against Drugs And Crime. (4) $1-67$. Recuperado de https://www.unodc.org/unodc/en/corruptio n/tools_and_publications/UN conventionagainst-corruption.html

Valles, D. (2015) La restitución de bienes incautados a organizaciones sindicales $y$ partidos políticosdurante el franquismo. Un análisis jurídico. Historia, Trabajo y Sociedad. (6). 51 -80. España. Recuperado de

https://dialnet.unirioja.es/descarga/articulo/ 5140044.pdf.
Vega, J. (2017). La lucha contra el lavado de activos y la medida de congelamiento de fondos como herramienta indispensable. Diálogo Con La Jurisprudencia. 22 (224) 33-39. Perú. Recuperado de https://works.bepress.com/javierwilfredoegacisneros/22/download/

Whisker, J, y Lokanan, M. (2019). Antimoney laundering and counter-terrorist financing threats posed by mobile money. Journal of Money Laundering Control. 22(1). 158-172. England. Recuperado de https://doi.org/10.1108/JMLC-10-20170061

Yáñez, D (2015). La medida cautelar innominada y anticipatoria en el proceso de responsabilidad del Estado por desplazamiento forzado en Colombia. Revistas Ius et Praxis. 21(2), 415-440. Recuperado de https://dx.doi.org/10.4067/S071800122015000200011

\section{Fuentes legales:}

Congreso de la República. (1992). D.L 768 Código Procesal Civil.

Ministerio de Justicia (2004) D.L 957, Código Procesal Penal del Perú.

Ministerio de Justicia (1991) D.L 935, Código Penal del Perú. 